This is the author's final, peer-reviewed manuscript as accepted for publication. The publisher-formatted version may be available through the publisher's web site or your institution's library.

\title{
Ethical judgments: what do we know, where do we go?
}

Peter E. Mudrack, E. Sharon Mason

\section{How to cite this manuscript}

If you make reference to this version of the manuscript, use the following information:

Mudrack, P. E., \& Mason, E. S. (2013). Ethical judgments: What do we know, where do we go? Retrieved from http://krex.ksu.edu

\section{Published Version Information}

Citation: Mudrack, P. E., \& Mason, E. S. (2013). Ethical judgments: What do we know, where do we go? Journal of Business Ethics, 115(3), 575-597.

Copyright: @ Springer Science+Business Media B.V. 2012

Digital Object Identifier (DOI): doi:10.1007/s10551-012-1426-z

Publisher's Link: http://link.springer.com/article/10.1007/s10551-012-1426-z

This item was retrieved from the K-State Research Exchange (K-REx), the institutional repository of Kansas State University. K-REx is available at http://krex.ksu.edu 
ETHICAL JUDGMENTS: WHAT DO WE KNOW, WHERE DO WE GO?

Peter E. Mudrack

Department of Management, Kansas State University

E. Sharon Mason

Brock University

KEY WORDS: Ethical Judgments, Literature Review, Vignettes 


\title{
ETHICAL JUDGMENTS: WHAT DO WE KNOW, WHERE DO WE GO?
}

\author{
Abstract \\ Investigations into ethical judgments generally seem fuzzy as to the relevant research domain. We first \\ attempted to clarify the construct and determine domain parameters. This attempt required addressing \\ difficulties associated with pinpointing relevant literature, most notably the varied nomenclature used to \\ refer to ethical judgments (individual evaluations of actions' ethicality). Given this variation in construct \\ nomenclature and the difficulties it presented in identifying pertinent focal studies, we elected to focus on \\ research that cited papers featuring prominent and often-used measures of ethical judgments (primarily, \\ but not exclusively, the Multidimensional Ethics Scale). Our review of these studies indicated a \\ preponderance of inferences and conclusions unwarranted by empirical evidence (likely attributable at \\ least partly to inconsistent nomenclature). Moreover, ethical judgments related consistently to few \\ respondent characteristics or any other variables, emergent relationships may not always be especially \\ meaningful, and much research seems inclined to repetition of already verified findings. Although we \\ concluded that knowledge about ethical judgments seems not to have advanced appreciably after decades \\ of investigation, we suggested a possible path forward that focuses on the content of what is actually \\ being judged as reflected in the myriad of vignettes used in the literature to elicit judgments.
}

RUNNING HEAD: Ethical Judgments 


\section{ETHICAL JUDGMENTS: WHAT DO WE KNOW, WHERE DO WE GO?}

Issues of fairness, justice, right and wrong are central to the subject of ethics (Carroll and Buchholtz, 2012), and evaluating the extent to which an action is right or wrong is the focus of ethical judgments. Ethical judgments refer to individual determinations of the appropriateness of a course of action that could possibly be interpreted as wrong (Reidenbach and Robin, 1990; Robin, Reidenbach, and Babin, 1997) or an individual's personal evaluation of the degree to which some behavior is ethical or unethical (Sparks and Pan, 2010). A typical method to access such evaluations in research is to present respondents with brief situations, scenarios, or vignettes in which a protagonist has committed or observed an ethically questionable act (107 of the first 1500 articles published in the Journal of Business Ethics alone used vignettes; Collins, 2000). The ultimate objective in investigating ethical judgments is "the explanation, prediction, and control of unethical behavior” (Flory, Phillips, Reidenbach, and Robin, 1993, p. 418). Making progress toward this important objective requires that prospective investigators be able to identify and retrieve relevant literature, synthesize this literature to pose research questions that have the potential to advance knowledge, use methodologies that enable meaningful insights to emerge, and draw appropriate conclusions from research findings. In the case of ethical judgments, the crucial first step involving literature retrieval is perhaps more daunting than might be apparent at a glance. As discussed later, other steps, particularly the one about drawing conclusions, seem daunting as well.

\section{Identifying and Retrieving Literature of General Relevance to Ethical Judgments}

A reasonable approach to begin the process of identifying and retrieving relevant literature is to consult review papers. For example, O’Fallon and Butterfield (2005, Table 3) compiled and summarized an extensive body of research dealing with judgment in the context of ethics. However, the pertinence of some of this research to the construct of ethical judgments as defined earlier is questionable. Some studies included in the review investigated moral reasoning (e.g., Eynon, Hill, and Stevens, 1997; Latif, 2000; Wimalasiri, Pavri, and Jalil, 1996), which differs from ethical judgments in its focus on the rationale behind choices, rather than the deemed appropriateness of specific choices (Kohlberg, 1976; Rest, 1979, 1986). Other reviewed research that addressed “ethical recognition” (Wu, 2003), an "ability 
to identify unethical behavior” (Larkin, 2000), and “cognitive frameworks” (i.e., factors considered when evaluating vignettes; McDonald and Pak, 1996) also seems not to have tapped into "ethical judgments”. Some “judgments” studies appeared consistent with behavioral intentions rather than judgments. For instance, Bateman, Fraedrich, and Iyer (2003) labeled as “moral judgment” the extent to which respondents “definitely would do it” (perform the ethically questionable action described), and Verbeke, Uwerkerk, and Peelen (1996, p. 1179) also invited subjects to address behavioral intentions ("what someone should do"). Other research featured responses to ethically-relevant scaled variables rather than to vignettes. Kaynama, King, and Smith (1996), for example, included items from Jones’ (1990) scale assessing the appropriateness of actions designed to advance one's own self-interest at the expense of employing organizations, and Cole and Smith (1996) used the Froelich and Kottke (1991) scale that solicits reactions to ethically questionable behaviors intended to benefit employing organizations. Recent research suggests, however, that these scales assess different constructs and have unique patterns of association with other measures (e.g., Mudrack and Mason, 2010). Moreover, the issue of comparability or equivalence of “judgments” based on survey items and “judgments” based on vignettes has neither been addressed nor resolved.

This discussion was not intended to criticize the work of O’Fallon and Butterfield (2005) but rather to illustrate the considerable barriers associated with identifying appropriate literature relevant to “ethical judgments”. Vitell and Ho (1997, p. 712), for example, found “only two studies ... that attempted to measure ethical judgments” but classified some studies dealing with such judgments as “deontological and teleological evaluations” (p. 711; see also Sparks and Pan, 2010, p. 412; Yoon, 2012). These may differ from ethical judgments at the construct level, but seem largely identical at the measurement level (e.g., $r=.75$; Pan and Sparks, 2012; other studies claiming to have assessed multiple constructs with different ethical judgments measures include Ayers and Kaplan, 2005, personal responsibility to perform a behavior; Haines, Street, and Haines, 2008, “moral obligation”; Mittal and Lassar, 2000, “sexual liberalism”; Reichert, LaTour, and Ford, 2011, attitudes toward advertisements; Schwepker and Good, 2011, “customer-oriented selling”). A vast array of empirical studies using a 
variety of methodological approaches could pertain to ethical judgments (that may not always be labeled as such), but the same construct may not necessarily have been assessed across different studies, and may even have different labels within the same study.

\section{INSERT TABLE 1 ABOUT HERE}

Another way to assemble applicable literature might be to consult the Social Sciences Citation Index (SSCI) to identify research that featured specific measures of ethical judgments and that would likely have cited seminal papers in which these measures first appeared. Much research reviewed by O’Fallon and Butterfield (2005; e.g., Wu, 2003), however, used self-developed single-item measures to record responses to a description of an ethically questionable activity (e.g., a five-point scale with "never acceptable” and “always acceptable” as end-points). Although single-item scales may often be adequate for assessing ethical judgments, such non-standardized measures do have unknown reliability and likely would be difficult for prospective investigators to locate through the SSCI or any other means. Indeed, Pan and Sparks (2012, Table 3) incorporated relatively few studies using single-item measures in their review and meta-analysis. Alternatives to such measures exist, however. For example, Reidenbach and Robin (1988, 1990; Reidenbach, Robin, and Dawson, 1991) created two versions of the Multidimensional Ethics Scale (MES) explicitly designed to assess “ethical judgments” (see Table 1), with the most recent version intended to supersede the earlier one. The MES is perhaps the best known measure in business ethics (Dunfee, 2006, p. 318), has been used in numerous investigations, was featured prominently in the recent review and meta-analysis of Pan and Sparks (2012), and appears to have good psychometric properties, such as high internal consistency and relatively weak associations with social desirability (e.g., Loo, 2002; Valentine and Barnett, 2007). Any subsequent investigation that used the MES would almost certainly have cited at least one of the aforementioned Reidenbach and Robin papers that described and illustrated the construct and associated measures. Therefore, the SSCI seems a useful tool to locate ethical judgments research, summarized later, that might otherwise be missed. When doing this, however, an interesting phenomenon emerged that might have remained hidden with other approaches to literature retrieval. 


\section{Nomenclature Issues in Literature Relevant to a Specific Ethical Judgments Measure}

One striking characteristic of empirical studies featuring the MES that we identified by means of the SSCI is the absence of consistent nomenclature to refer to the construct of interest. As outlined in Table 2, investigators have used over three dozen different labels to designate the construct assessed with MES survey items that permit respondents to judge an action’s ethicality (“ethical judgments” according to the scale developers). Some labels seem generally synonymous with ethical judgments (e.g., ethical evaluations). Others, however, provide little direct indication of any relevance to judgments (e.g., moral philosophy, ethical awareness, ethical sensitivity, individual moral value frameworks).

\section{INSERT TABLE 2 ABOUT HERE}

A perplexing array of labels for what appears to be the same construct suggests that germane literature might understandably be overlooked by potential investigators searching simply for "ethical judgments”. For example, O’Fallon and Butterfield (2005) omitted several relevant papers from the time period of their review (identified below) that we were able to locate by means of the SSCI (Pan and Sparks (2012) also left out several pertinent studies in their review; e.g., Clark and Dawson, 1996; Cohen, Pant, and Sharp, 1998; Davis, Andersen, and Curtis, 2001). What these papers had in common, apart from empirical results derived from MES survey items which the scale’s developers referred to as “ethical judgments”, were labels that conveyed little to no indication of applicability to judgments in the context of ethics. Beekun, Stedham, and Yamamura (2003, p. 276), for example, indicated that they had assessed criteria “used to evaluate the ethical content of a decision”. Bucar, Glas, and Hisrich (2003, p. 276) measured ethical “responsiveness” and “sensitivity”. Cohen et al. (1998, p. 254) examined “ethical orientation on a number of moral constructs" (but also stated that "the MES is a measure of ethical judgment”, p. 255). Herndon, Fraedrich, and Yeh (2001, p. 76) assessed “individual moral values” with MES survey items (see also Fennell and Malloy, 1999; Landeros and Plank, 1996; LaTour, Snipes, and Bliss, 1996; Loo, 2002; Mittal and Lassar, 2000; Sarwono and Armstrong, 2001; Schwepker, 1999; Schwepker, Farrell, and Ingram, 1997; Schwepker and Ingram, 1996; Snipes, LaTour, and Bliss, 1999). Nomenclature inconsistencies may very well have caused these papers to have been omitted from 
O’Fallon and Butterfield's (2005) review of judgments in the context of ethics, which suggests that a comprehensive review of literature relevant to a broad conceptualization of ethical judgments may be well-nigh impossible to attain. A practical resolution to this impasse may be to focus more on research that employed specific measures such as the MES in order to identify applicable literature that might otherwise be missed. The results of such a review are addressed below.

\section{Implications of Inconsistent Nomenclature}

As discussed, an obvious repercussion of diverse nomenclature to refer to ethical judgments is the difficulty or even impossibility of conducting a comprehensive broad-based literature review.

Implications seem likely to extend beyond this crucial issue, however. In any research report, valid conclusions emerge directly and unambiguously from the empirical evidence and unwarranted inferences are avoided by authors. Nomenclature suggesting that a construct other than ethical judgments has been assessed with a measure of ethical judgments serves to increase the likelihood of invalid conclusions. If ethical judgments are labeled as “ethical awareness”, then a paper’s authors might be inclined to draw inappropriate conclusions about “awareness”. We put forward a few illustrative examples. Tsalikis and Ortiz-Buonafina (1990, p. 513-515) concluded that "females are more ethically sensitive than their male counterparts” (emphasis added), but as MES survey items do not assess “sensitivity”, such an assertion, whether valid or not, has no connection with empirical findings (see also Stevenson and Bodkin, 1998, p. 49). Although, based on results from MES survey data, Schwepker and Ingram (1996, p. 1155) reported that “salespeople making more ethical decisions indicate higher performance levels” (emphasis added), respondents made no actual "decisions”. Sarwono and Armstrong (2001, p. 48) noted that the higher the Religious Value Orientation, "the more likely the individual is to perceive business problems with ethical dilemmas”. The MES does not assess an ability to perceive problems. Cohen et al. (1998, p. 265) suggested that accounting majors exhibited "higher sensitivity to the presence of” relativism, but the MES does not measure sensitivity to any form of presence. Bucar et al. (2003, p. 276) indicated that most of their respondents “correctly considered the 'fair-unfair' dimension as a 'pure' ethical assessment, while the 'good-bad' dimension was considered as a matter of practical consequences for the business”. MES 
survey items do not measure the types of ethical assessments "considered", the "perceived seriousness of the transgressions” (Tsalikis, Seaton, and Shepherd, 2001, p. 241), "the degree that individuals emphasize various moral criteria when making ethical judgments” (Davis et al., 2001, p. 44, Hypothesis 8), or "whether respondents in general thought the vignette was negative from an ethical perspective” (Landeros and Plank, 1996, p. 795). Moreover, these do not "allow respondents to provide explanations for their moral and other judgments” (Shawver and Sennetti, 2009, Abstract), and do not specifically identify “rationale(s) behind moral reasoning and why respondents believe a particular action is ethical” (Cohen et al., 1998, p. 254). Instead, these items simply allow respondents to indicate the extent to which they believe ethically questionable activities depicted in vignettes are "fair”, “acceptable to one’s family”, or "traditionally unacceptable”; that is, respondents judge or evaluate the degree to which they regard these as right or wrong (see Table 1). Differences in MES scores suggest only that some people interpreted such activities as more or less “fair” than others. As stated succinctly by Barnett, Bass, and Brown (1996, p. 1166): “Reidenbach and Robin's scale is designed to allow respondents to express the level to which they believe an action or actions is morally acceptable”.

Moreover, it may not be entirely appropriate for authors to judge, or even to appear to judge, respondent ethics by suggesting that some courses of action evaluated by respondents are normatively correct or incorrect. As discussed above, Schwepker and Ingram (1996) explicitly mentioned salespeople that made "more ethical decisions", but this seems to presume both that some decisions are "better" than others in terms of ethics, and that researchers are qualified to make this assessment. Such "judgmental" labeling tendencies occur regularly (e.g., “The respondent who correctly recognizes the questionable action” (Shawver and Sennetti, 2009, p. 674) or “took an ethical action” (Landeros and Plank, 1996, p. 796, emphasis added; see also Fleischman and Valentine, 2003, p. 38; Ge and Thomas, 2008, p. 198; Hsu, Fang, and Lee, 2009, p. 160; Hudson, 2007, p. 391; Kaplan, Samuels, and Thorne, 2009, p. 393; Oumlil and Balloun, 2009, p. 466; Radtke, 2000, p. 304). As suggested by McDonald (2000, p. 96), “an individual should not be labeled 'unethical' in a general sense” regardless of any pattern of scores on any measure designed to assess ethical attitudes or judgments. Labeling decisions, choices, or responses 
made by individuals as "unethical” or "inappropriate” also seems inappropriately to label the individuals themselves and also to insert researchers' personal views as referents for this process.

Unwarranted inferences of little apparent relevance to judgments also seem to creep into research reports when discussing empirical results emerging from the MES regardless of what label has been attached to the construct of interest. MES data do not permit any conclusions to be drawn about what individuals “relied upon”, “incorporated”, “used”, or "perceived”. Again, these merely "allow respondents to express the level to which they believe an action or actions is morally acceptable” (Barnett et al., 1996, p. 1166). Table 3 provides examples of such inferences (that seem pervasive in the literature), as well as alternative interpretations of the same findings derived from what has actually been assessed with MES survey items (see Table 1). As suggested by such alternative interpretations, conclusions derived from ethical judgments research often seem more trivial and mundane than might be apparent at a glance.

\section{INSERT TABLE 3 ABOUT HERE}

Our purpose here was not to be pedantic or unnecessarily critical of author word choices but rather to advance knowledge concerning ethical judgments. Knowledge advancement requires potential investigators be able both to retrieve relevant literature and to have confidence in conclusions drawn from this literature. Any words or phrases suggesting that a construct other than ethical judgments has been assessed with an ethical judgments measure potentially hinder the development of knowledge in this important area. "Responsiveness” and "sensitivity”, for example, are not simply synonyms for “judgment”. The proliferation of labels and designations for what appears to be the same underlying construct that was assessed with MES survey items indeed seems perplexing, and the desirability of appropriate and consistent nomenclature seems self-evident. After almost a quarter century of research using the MES, we recommend, regardless of whether or not the MES has been used, that investigators adopt the terminology offered by Reidenbach and Robin $(1988,1990)$ to refer to the construct involving judgments of an action's ethicality; that is, “ethical judgments”.

If authors who appear to have assessed ethical judgments have not always indicated this 
explicitly, and have often drawn inferences that seem disconnected from actual findings (as discussed, see also Table 3), then what can be learned from relevant studies in light of this understanding? As mentioned, some research conclusions perhaps seem trivial, but a more definite assertion on the matter awaits a more comprehensive review. We examined research findings based on empirical studies into ethical judgments that cited Reidenbach and Robin (1988, 1990; Reidenbach et al., 1991; also Dabholkar and Kellaris, 1992) and that used multiple items, primarily derived from the MES, to assess these. We identified these studies with the assistance of the SSCI (as well as with Google Scholar, and searches of the citations listed in identified papers). Before discussing these findings, we first highlight the essential results of the more recent of Reidenbach and Robin’s $(1988,1990)$ seminal papers.

\section{Reidenbach and Robin (1990)}

Reidenbach and Robin’s (1990) refined an earlier, far lengthier, version of the Multidimensional Ethics Scale (MES) with the help of factor analytic techniques and debriefing conversations with respondents. The original pool of 33 items consistent with five "strains of moral philosophy" (Reidenbach and Robin, 1988) shrank to the eight items in three scales that appear in Table 1. Beyond scale development, the 1990 paper reported that moral equity, relativism, and contractualism scores correlated positively and strongly with overall ethical evaluations (“univariate” measure) and behavioral intentions (both assessed with single-item scales). In different words, individuals who regarded the questionable activities depicted in the vignettes as “unfair”, not "traditionally acceptable” or as "violating an unspoken promise” tended to view the same actions as "unethical” and as something that they themselves would not likely perform. This foundational work, although important and necessary, basically determined that individuals faced with ethical dilemmas respond consistently on alternative measures of the same (or highly similar) basic construct(s). Activities that seem (in)appropriate on one indicator seem (in)appropriate on others, and individuals are unlikely to indicate that they personally would perform an activity that seems wrong to them. In data from ten samples, Robin, Reidenbach, and Babin (1997) reported weighted average correlations of .61 between moral equity and relativism, .52 between moral equity and contractualism, and .40 between relativism and contractualism. 


\section{Replicating Reidenbach and Robin (1990)—Ethical Judgments and Behavioral Intentions}

We identified 20 subsequent studies (designated with an "R" for "replicate” in the list of references) that essentially only replicated and verified these findings that seemed eminently reasonable and logical the first time they were presented. Other studies, 23 by our count (specific citations available on request), reported strong relationships in the context of testing a variety of different hypotheses involving ethical judgments, with ambiguity occasionally introduced by attaching negative signs to some correlations (see Note for further discussion). We also located 29 studies, likewise identified in the list of references and designated with an " $\mathrm{H}$ ” for "hypothesis", which went beyond simple reporting of such relationships by advancing specific hypotheses concerning connections between ethical judgments and behavioral intentions that generally received overwhelming empirical support. The only exceptions to this support occurred in the context of a study using a complex "MES measurement model with three dimensions, three scenario factors, and residuals of identical items allowed to correlate” (Nguyen and Biderman, 2008, p. 630) and one in which the activity being evaluated (customers bringing their own shopping bags to stores) seemed not to be ethically questionable (Chan et al., 2008). Other studies relevant to advertising and marketing have examined relationships between ethical judgments and behavioral intentions framed as “purchase intentions” (e.g., Henthorne and LaTour, 1995; LaTour and Henthorne, 1994; Simpson, Brown, and Widing, 1998).

Linkages between ethical judgments and behavioral intentions first appeared in the published literature in 1990, and have been verified many times since then. Advancing and testing hypotheses about relationships that have seemingly been well understood for decades makes only a modest contribution to the advancement of knowledge about ethical judgments, despite McMahon and Harvey (2007a, p. 352) describing connections between such judgments and behavioral intentions as "perhaps the most interesting good news provided by Study 2”. The need for such hypotheses may in fact have ended shortly after the publication of Reidenbach and Robin's (1990) findings. As stated by Duska (1996, p. 316, note 25): “The link between moral equity and behavioral intention is said to be statistically significant and substantial for all three scenarios, but what does that tell us?” Sometimes even rhetorical 
questions require an answer: nothing that was not plainly evident in 1990. We now turn to reports of connections between ethical judgments and various characteristics of respondents that have been examined in the literature, followed by a summary of other research themes. As will become apparent, findings from the ethical judgments literature have largely been inconsistent at best.

\section{Ethical Judgments and Respondent Characteristics}

\section{Gender}

Women were more likely than men to view ethically questionable business practices as inappropriate in 22 of 24 vignettes used by Barnett, Brown, and Bass (1994) and in nine vignettes employed by Knotts, Lopez, and Mesak (2000), and were more inclined than men to regard an ethically questionable promotion decision in which a qualified woman candidate was passed over for promotion as wrong (Valentine and Page, 2006). Cohen, Pant, and Sharp (2001, p. 329, “women consistently viewed the [ethically questionable] acts as less ethical” than men) and Eweje and Brunton (2010, p. 105, “females appear to demonstrate a greater sensitivity in ethical awareness”) reported similar conclusions but provided no specific results relevant to gender (see also Oumlil and Balloun, 2009). Marques and Azvedo-Pereira (2009, p. 236) also furnished no specific results, but seemed to report the opposite finding by claiming that men were "stricter ... when making ethical judgments".

Other studies, however, have been unable to duplicate this level of consistent responding. Women interpreted ethically questionable activities as less acceptable than men in one of four vignettes (Tsalikis and Ortiz-Buonafina, 1990), in two of eight vignettes (Cohen et al., 1998, Table 3), in one of eight vignettes (Radtke, 2000; behavioral intentions only), and in one of three vignettes (Loo, 2001, 2002; the opposite result emerged with a different vignette). Nguyen, Basuray, Smith, Kopka, and McCulloh (2007) specifically examined gender differences in ethical judgments, but the largest reported relevant correlation in three vignettes was -.18 (three of nine such correlations also had positive signs). Similarly, Valentine and Rittenburg (2007) uncovered a correlation of -.10 between moral equity and gender (see also Barnett and Valentine, 2004; Shafer, 2008, Table 1). Pan and Sparks (2012) reported a corrected weighted correlation of .19 between ethical judgments and gender, but omitted five aforementioned 
studies reporting weak results in their review. In summary, the overall conclusion offered by O'Fallon and Butterfield (2005, p. 379) remains applicable.

Conclusion: There are often no differences between women and men in ethical judgments, but when differences do occur women seem inclined to judge questionable activities as less appropriate than men.

\section{Religiosity}

Knotts et al. (2000) reported that, relative to students with lower intrinsic religious commitment, high commitment students were more inclined to view questionable activities as wrong. Such a result, however, has not appeared consistently in other studies (with the exception of recent studies examining judgments concerning the appropriateness of business support of controversial issues such as same-sex marriage; Swimberghe, Flurry, and Parker, 2011; Swimberghe, Sharma, and Flurry, 2011). Clark and Dawson (1996, p. 363), for example, predicted that intrinsically religious persons would evaluate the questionable actions depicted specifically in two of three vignettes as less ethically appropriate than nonreligious persons (p. 363), but the opposite result emerged, which led to speculation that, for example, intrinsically religious persons might be undemanding of others (pp. 366-368). Ethical judgment was orthogonal to religiosity in whistle blowing vignettes (Barnett et al., 1996; Chiu, 2003), with the latter study providing no details about this measure. Highly religious persons judged dubious activities as wrong in only one of both Razzaque and Hwee's (2002) six vignettes and Wagner and Sanders' (2001) seven vignettes (results from only one vignette actually appeared in the paper, and "high religion” was inappropriately equated with “conservative religious beliefs”, p. 165), and in no vignette employed by either Oumlil and Balloun (2009, p. 471) or Rottig, Koufteros, and Umphress (2011). Sarwono and Armstrong (2001) reported a weak correlation $(r=.17)$ between ethical judgments and religious value orientation. Pan and Sparks (2012) did not include results from five aforementioned studies in their metaanalysis, but nonetheless found no significant relationship between ethical judgments and religiosity.

Conclusion: There is little evidence that ethical judgments relate systematically with respondent religiosity. 


\section{Ethical Ideologies (Idealism and Relativism)}

Ethical idealism refers to beliefs that performing the "right” action will invariably produce desirable outcomes and that harming another person is always wrong (Forsyth, 1980). Idealists often interpret questionable activities as ethically inappropriate (Barnett et al., 1994, 21 of 26 vignettes considered; Barnett, Bass, Brown, and Hebert, 1998, three vignettes; Bass et al., 1999, two vignettes; Davis et al., 2001, 5 vignettes in Study 1 (three “moral judgments” items) but only one of three vignettes in Study 2 (MES items; idealism was associated with approval of the questionable activity in another vignette, p. 46; Kleiser, Sivadas, Kellaris, and Dahlstrom, 2003, two vignettes, somewhat weaker connections with Forsyth measure than with the self-created Marketing Ethical Ideologies scale; Mudrack, Bloodgood, and Turnley, 2012; Singh, Vitell, Al-Khatib, and Clark, 2007, four vignettes, strongest $r=.23$; Vitell and Patwardhan, 2008, two of four vignettes in European sample, behavioral intentions only; see also Dubinsky, Nataraajan, and Huang, 2004). Other studies using accounting vignettes and conducted outside of North America, however, were unable to detect significant associations between idealism and ethical judgments (Marques and Azvedo-Pereira, 2009, Portugal; Shafer, 2008, Table 1, China). Idealism was orthogonal to ethical judgments in a real estate vignette (Boyle, 2000), physician behavioral intentions in health care vignettes (Eastman, Eastman, and Tolson, 2001), and also to behavioral intentions in a bribery vignette (Valentine and Bateman, 2011) and a file sharing vignette (Bateman, Valentine, and Rittenburg, in press), and in four vignettes in a Chinese sample (Vitell and Patwardhan, 2008; see also Singhapakdi, Vitell, and Franke, 1999). Idealists, however, regarded reporting someone else's ethically questionable action (blowing the whistle) as ethically appropriate (Barnett et al., 1996; Chiu and Erdener, 2003). Pan and Sparks (2012) reported a correlation of .22 between idealism and ethical judgments in nine samples.

Ethical relativism is the extent to which universal moral rules are rejected because of the believed different ways to look at moral issues (Forsyth, 1980). Although highly relativistic persons might seem inclined to interpret questionable actions as ethically appropriate, observed relationships between relativism and ethical judgments have, with the specific exception of Kleiser et al. (2003), generally been 
weak. Barnett et al. (1994) reported no significant relationships out of 26 vignettes examined (Table 1; two relatively large correlations for Vignettes 1 and 3 may have resulted from a misprint), Barnett et al. (1998) found statistically significant, but weak $(r<.20)$, relationships in three vignettes, Davis et al. (2001) indicated two significant relationships out of eight vignettes across two studies, and Singh et al. (2007) reported two significant relationships out of four vignettes. Weak or nonsignificant relationships were reported by Bass, Barnett, and Brown (1999), Dubinsky et al. (2004), Eastman et al. (2001, behavioral intentions only), Marques and Azevedo-Pereira (2009), Shafer (2008), Singhapakdi et al. (1999, intentions only), Valentine and Bateman (2011; intentions only), and Valentine and Patwardhan (2008; intentions only). Chiu and Erdener (2003) found that, contrary to predictions (p. 349), high relativists resembled high idealists in terms of regarding whistle blowing as ethically appropriate (Barnett et al., 1996 reported a nonsignificant relationship with relativism in a whistle blowing vignette). Pan and Sparks (2012) reported a weighted average (corrected) correlation of -..135 between ethical judgments and relativism, but omitted results from five aforementioned studies.

Some research has categorized individuals based on combinations of their idealism and relativism scores. For example, as determined by median splits, “absolutists” (high idealism and low relativism) were inclined to view the dubious actions described in two vignettes used by Tansey, Brown, Hyman, and Dawson (1994) as less acceptable than did “subjectivists” (low idealism and high relativism). However, “exceptionists” (low idealism and relativism) differed little from "absolutists” who also are characterized by low relativism (Table 5, p. 71). Oumlil and Balloun (2009) collected data on ethical idealism and relativism, and also reactions to vignettes, but did not report on possible connections between these. Conclusion: Ethical idealists tend to regard many, but not all, ethically questionable activities as wrong (whistle blowing is not as "ethically questionable” as the activity being reported), but there is little evidence that ethical judgments relate systematically with respondent relativism.

\section{Machiavellianism}

Machiavellianism is a personality trait that seems unambiguously associated with the endorsement of ethically questionable behaviors and attitudes (Christie and Geis, 1970), except in the area 
of ethical judgments. High Machiavellianism was linked with ethical judgments as might be expected in only one of six vignettes, and only on the contractualism dimension (Razzaque and Hwee, 2002).

Respondent Machiavellianism was orthogonal to ethical judgments when evaluating a recommendation to hire “young attractive Hispanics” (Schepers, 2003, p. 343) for a chain of Mexican themed restaurants in order to increase sales. Here, the absence of an expected relationship may have been attributable to the weak conceptual connection between such a recommendation and the manipulative tendencies of Machiavellians, the absence of apparent harms created by such a policy, and ambiguity about precisely what respondents were asked to judge; that is, the hiring policy itself (“[P]articipants were asked ... how they personally perceived such a hiring policy”) or the sharing of this policy with store managers (pretest results "indicated that the choice to give site managers the information [that such a policy increased sales] was considered unethical”; Schepers, 2003, p. 344). Weak relationships between ethical judgments and Machiavellianism have also been noted by Bass et al. (1999) and McMahon and Cohen (2009, single item judgments measure; Shafer and Simmons (2008) reported somewhat stronger relationships also using a single item judgments measure and Mudrack et al. (2012) also uncovered a relatively strong association). Pan and Sparks (2012) reported a weighted average (corrected) correlation of -.16 between ethical judgments and Machiavellianism, but omitted results reported by Razzaque and Hwee (2002). Conclusion: There is little evidence that ethical judgments relate systematically to respondent Machiavellianism.

\section{Locus of Control}

Locus of control has emerged as orthogonal to ethical judgments in six vignettes (Razzaque and Hwee, 2002), in two vignettes (Bass et al., 1999), in five of six vignettes relevant to credit card use (Ding, Chang, and Liu, 2009), and in a whistle blowing vignette (Chiu, 2003). Chiu and Erdener (2003), also in the context of whistle blowing, reported that locus of control correlated positively with ethical judgments in the Hong Kong sample, and negatively with behavioral intentions in the Shanghai sample. These results were ambiguous, however, as neither the precise meaning of high and low scores on locus of control, nor the precise implications of positive or negative relationships involving locus of control, were 
specified. Cherry (2006, p. 124) discovered that although internally controlled Taiwanese respondents tended to judge bribery as wrong, they also seemed inclined to engage in bribery themselves. No connections between ethical judgments and locus of control, however, appeared in an American sample, and Cherry and Fraedrich (2000) reported a weak relationship ( $r=-.14)$. Pan and Sparks (2012) computed a weighted average (corrected) correlation of -.07 between ethical judgments and locus of control, but omitted results from four aforementioned studies.

Conclusion: There is little evidence that ethical judgments relate systematically to respondent locus of control.

\section{Moral Reasoning}

Six of Robin, Gordon, Jordan, and Reidenbach's (1996) nine vignettes emerged from the Defining Issues Test (DIT) designed to assess moral reasoning. MES scores emerged as better predictors of behavioral intentions than did moral reasoning $(\mathrm{P})$ scores, which is unsurprising in that moral reasoning assesses the complexity of the rationale used to make decisions with moral content rather than ethical judgments (Rest, 1979, 1986), and, as discussed, ethical judgments relate strongly with behavioral intentions. P scores predicted both overall ethics scores and behavioral intentions in one vignette. Although the interaction between P scores and U (utilizer) scores (Thoma, Rest, and Davison, 1991) also predicted intentions and judgments, the nature of this interaction was neither described nor depicted. Ge and Thomas (2008) assessed moral reasoning with an accounting-specific DIT and expected "P scores” to relate positively with ethical judgments (Hypothesis 3, p. 195). Although scores on two of three ethical judgments scales “were found to be positively related to deliberative reasoning (Table VIII)” (p. 198), all relevant regression coefficients had negative signs (Table 8, p. 201, emphasis added). Shawver and Sennetti (2009) reported a weak relationship between moral reasoning and composite ethical judgments $(r$ $=.18$ ) in one of eight vignettes examined, and Wagner and Sanders (2001) reported no significant results involving moral reasoning. Schmidt, McAdams, and Foster (2009) assessed both ethical judgments and moral reasoning, but did not report linkages between them.

Conclusion: There is little evidence that ethical judgments relate systematically to respondent moral 
reasoning.

\section{Other Respondent Characteristics}

Schwepker and Ingram (1996) determined that salespeople who interpreted the ethically questionable activities described in three sales vignettes (only one of which was actually described) as inappropriate on six MES items tended also to score highly on self-rated performance (similar results appeared in Schwepker and Good, 2011). This relationship was strongest among men, unmarried respondents, persons over the age of 40, and those with a college education.

Hypercompetitive persons with a "win at all costs” approach tended to regard ethically questionable activities as appropriate, but personal development competitors who view competition as a means of self-discovery interpreted such dubious activities as inappropriate (Mudrack et al., 2012).

Bateman et al. (in press) predicted, but did not find, that respondent “formalism” (i.e., the importance attached to various traits of apparent relevance to ethics such as "being dependable”) would be associated with behavioral intentions in a file sharing vignette.

Conclusion: Far more research is needed before any firm, or even tentative, conclusions can emerge regarding connections between ethical judgments and either performance or formalism. Relationships with competitiveness, however, seem a promising avenue for further exploration.

\section{Respondent Determined Ethical Climate}

Survey respondents are sometimes asked to describe their organization's ethical climate. The few investigations that have assessed this with the Ethical Climate Questionnaire (ECQ) have reported weak and inconsistent results. Barnett and Vaicys (2000) reported no significant relationships between either ethical judgments or behavioral intentions (one vignette) and four climate dimensions. These authors determined that the judgments-intentions relationship was stronger when perceptions of team and social responsibility climate were low rather than high, but the observed moderating effect was opposite to that hypothesized. Herndon et al. (2001) indicated that high scorers on "individual moral values” (i.e., persons who regarded questionable activities as ethically inappropriate), were inclined to perceive high levels of ethics in their Taiwanese retail organizations (both determined on the basis of median splits), but 
seemingly did not examine separate ECQ dimensions. Shafer (2008) reported one significant relationship involving four climate dimensions across three ethical judgments indicators. Schwepker et al. (1997) examined both ethical judgments and ethical climate, but did not link the two.

Some research has examined "perceptions of the ethical environment” in respondents' own employing organizations (e.g., Barnett and Valentine, 2004; Razzaque and Hwee, 2002; Zhang, Chiu, and Wei, 2009a,b). Here, individuals assess, for example, the extent to which both managers and organizations “reward ethics”, “take ethics seriously”, have "high ethical standards”, and are "concerned with ethics”. Without some indication of precisely what employing organizations did when they “rewarded ethics” or how frequently and visibly this occurs, or what "high standards” or "concern” might imply and how respondents could determine that someone else has these, there seems no way to gauge what survey responses might actually mean or whether these are comparable or equivalent across different people. Reactions to such items may reveal more about individuals themselves and what they would like to be true in their organizations rather than about "actual ethical climate”. Moreover, relationships between such perceptions and ethical judgments have tended to be modest (e.g., $r=.19, .11$; Barnett and Valentine, 2004; see also Valentine and Barnett, 2007; Razzaque and Hwee, 2002, and Zhang et al., 2009a). Pan and Sparks (2012) reported a weighted average (corrected) correlation of .10 between ethical judgments and “ethical environment”.

Conclusion: There is little evidence that ethical judgments relate systematically to respondentdetermined ethical climate.

\section{Respondent Determined Situational Characteristics}

Research has attempted to explore connections between ethical judgments and characteristics of situations that might influence such judgments (e.g., the magnitude of an action's consequences, social consensus, probability of effect, temporal immediacy, proximity, concentration of effect; cf. Jones, 1991). One approach used regularly to assess situational characteristics is to ask respondents themselves for their interpretations of a vignette, which then becomes their own individual "perceived situational characteristics” score. To assess magnitude of consequences, for example, persons might be asked to 
indicate the degree to which they believe that the harm resulting from a questionable action would be minor or severe (Barnett and Valentine, 2004). Although intended to assess situational characteristics, such an approach may reveal far more about respondents themselves than about situations, and thus more accurately qualify as a respondent characteristic. After all, different people may have idiosyncratic interpretations of such things as "severe consequences", especially when it seems impossible actually to determine these conclusively (as discussed below).

There are two interrelated problems and ambiguities with this approach (beyond the possibilities of simple “common method variance” that results when judgments and situational characteristics emerge from the same source, and the aforementioned idiosyncratic interpretations) that call into question the construct validity of such measures and cast doubt on the extent to which any results that accrue advance knowledge about ethical judgments. First, respondents are asked to provide opinions about matters which are often unknown and unknowable based on the information available. Second, the presumed cause and effect relationship--that consequences of varying magnitudes, for example, influence interpretations of an action's ethicality (e.g., "by focusing on PIE [perceived importance of an ethical issue], managers will be able to directly affect employee judgment and, indirectly, moral intent”, Haines et al., 2008, p. 396; see also Barnett, 2001, p. 1038; Chen et al., 2009, p. 370; Pan and Sparks, 2012, p. 86; Valentine and Fleischman, 2003, p. 329; Valentine and Hollingsworth, 2012, p. 520; Vitell et al., 2003, p. 166)--may not necessarily always hold. The work of Shaw (2003) will be discussed purely to illustrate these points.

Shaw (2003) used a vignette in which a company sells personal information collected through its web site to other companies without the knowledge or consent of the individuals providing the information. One of the measures was "magnitude of organizational effect”, which was the extent of respondent agreement that the organization would experience each of eight outcomes if it behaved as described above (cf. "probability of effect”, Jones, 1991). Three of the items were "failing to attract new customers”, “declining profits”, and “rising costs”. Survey respondents could perhaps realistically offer opinions as to whether the risks associated with these possible outcomes seemed to justify, to them, the additional short-term revenues derived from such sales. Smith, Simpson, and Huang (2007, pp. 650-651), 
for example, asked respondents to estimate the extent to which being discovered having performed questionable acts would create problems in their own lives. However, there is no way for any respondent to ascertain whether an organization would actually experience such outcomes, and thus this measure's construct validity seems doubtful in that it does not assess "magnitude (or even probability) of organizational effect”, and certainly not in the way intended by Jones (1991); that is, as objective attributes of situations. Similarly, there seems no way for any individual to provide meaningful estimates concerning the likelihood of formal sanctions or other outcomes (Smith et al., 2007, p. 646), the extent of perceived “moral intensity” (a composite of Jones’ situational characteristics as determined by respondents; e.g., Chen, Pan, and Pan, 2009; Valentine and Fleischman, 2003; Valentine, Fleischman, Sprague, and Godkin, 2010; Valentine and Bateman, 2011; Vitell, Bakir, Paolillo, Hidalgo, Al-Khatib, and Rawwas, 2003), or any component characteristic such as “temporal immediacy” (whether anticipated consequences of the questionable action in the vignette would occur immediately or much later) or "proximity” (to what extent are those affected by questionable actions similar to respondents themselves). Nomenclature issues also return to the forefront here, as Shaw's (2003) "magnitude of organizational effect” was called “attitude” by Cherry (2006), “consequential evaluations” by Cherry and Fraedrich (2002) and “teleological evaluations” by Cherry, Lee, and Chien (2003) and Chan, Wong, and Leung (2008). The “teological evaluations” of Rallapalli, Vitell, and Barnes (1998, p. 161) asked respondents to evaluate provided alternatives simply in terms of how "good" or "bad" they were, and thus seems more closely to resemble ethical judgments. Valentine and Rittenburg (2004) also used the phrase "teleological evaluations" to refer to the extent to which ethically questionable actions maximize benefits and provide the greatest utility. This was labeled as “utilitarianism” by Reidenbach and Robin (1988), but relevant items were later removed from the revised MES because individuals apparently had difficulty responding meaningfully to these specific items (Reidenbach and Robin, 1990, p. 647).

Moreover, perceived “magnitude of consequences/organizational effect” as determined by Shaw's (2003) respondents may not necessarily influence ethical judgments as typically presumed because the causal direction could be reversed. Great and definite harms generally make an activity more ethically 
problematic than small and unlikely harms, and ethics researchers probably are not alone in understanding this. Persons who believed that the situation described by Shaw (2003) was (or was not) unethical might, in order to respond consistently, follow this judgment by concurring that such activities must (or must not) have created significant harms, particularly when the actual likelihood of such harms occurring seems unknown and unknowable. Ethical judgments, therefore, could affect respondent assessments of factors presumed to influence an action's ethicality (cf. Staw, 1975). This could also be true even if ethical judgments appeared last on a survey, as readers might form initial impressions of the "rightness" of behaviors described in vignettes even before being asked specifically about such matters. Given the absence of research, for example, into how quickly judgments form, this discussion has of necessity been speculative. However, research that features situational characteristics provided by respondents has been unable to rule out this alternative causal direction and has seemingly overlooked any possibility other than the one in which ethical judgments are influenced by respondent-determined situational characteristics.

Research has found, for example, that ethical judgments have typically correlated strongly with “magnitude of organizational effect” ( $r=.53, .26$, Shaw, 2003), “magnitude of consequences” (Barnett and Valentine, 2004, $r=.40, .47$; McMahon and Harvey, 2007a, intentions only), and "seriousness of consequences” (Barnett, 2001, $r=-.33$, -.39), all of which seem intended to assess the same construct. "Moral intensity”, a composite measure of various situational characteristics, has also correlated strongly with ethical judgments (e.g., Taylor and Curtis, 2010, $r=.64$, intentions only; Valentine and Hollingsworth, 2012, $r=.60, .55$; Valentine et al., 2010, $r=.49, .60$; Vitell et al., 2003, $r=.53, .57, .68$; Vitell and Patwardhan, 2008). Nguyen and Biderman (2008) attempted to draw conclusions about moral intensity (see also Nguyen et al., 2008) “without actually measuring the moral intensity construct” (p. 637). In contrast, ethical judgments have largely been orthogonal to "temporal immediacy" (Barnett, 2001, $r=-.09$, -.15), and "proximity” (Barnett, 2001, $r=.17, .01$; Valentine and Hollingsworth, 2012, $r=$ .02, -.07; Vitell and Patwardhan, 2008, intentions only). Pan and Sparks (2012) reported a weighted average (corrected) correlation of .72 between ethical judgments and moral intensity (six studies). Conclusion: Observed relationships between ethical judgments and respondent-determined situational 
characteristics may not be particularly meaningful. The construct validity of measures that ask about matters that are unknown and unknowable with available information (e.g., elapsed time before anticipated consequences occur) seems suspect, and until research is able to rule out the possibility that ethical judgments influence perceived situational characteristics, specific assertions of causality that such characteristics influence judgments seem inappropriate and premature. This research stream may have done little more than verify the well-established finding that individuals tend to respond consistently when faced with vignettes depicting ethically questionable activities.

\section{Respondent Determined Social Consensus}

One situational characteristic identified by Jones (1991) but not addressed until now is "social consensus”. As a perception, this has meant the degree to which respondents feel that society as a whole might consider an action as right or wrong (Barnett, 2001; Barnett and Valentine, 2004). As stated by these authors (p. 345), “Jones (1991) argues that individuals look to societal norms to reduce ambiguity when confronted with ethical dilemmas”. People undoubtedly do exactly this, but the construct represented by “social consensus” survey items does not tap into this implied process of comparison with actual societal norms. As with the preceding discussion, there seems no way to ascertain whether respondents are even aware of such norms or have understood these accurately. Dunfee (2006, p. 308) noted that "to date, it is a fair conclusion that some of those applying ISCT [integrative social contracts theory] have had nontrivial difficulties in identifying hypernorms” (i.e., values acceptable to all cultures and organizations). Presumably, determining the degree to which society considers any action as right or wrong may be subject to similar difficulties. Moreover, the direction of presumed causality--that social consensus influences ethical judgments--may also be reversed as addressed previously. Persons who interpret a questionable activity as wrong (or not wrong) may simply be offering a "reason" for this judgment (the apparent social consensus) in an implicit, or even explicit, desire to respond consistently.

However, an additional interpretive difficulty is that the construct represented by perceived social consensus may be largely, or even totally, congruent with ethical judgments themselves. These include beliefs about the extent to which actions are culturally and traditionally acceptable (see Table 1), and such 
assessments do not differ appreciably from judgments about societal, organizational, or professional acceptance of actions (that is, perceived social consensus). "Subjective norms” (Cherry and Fraedrich, 2000; also called “normative pressures from the in-group”, Cherry et al., 2003, Hypothesis 5; see also Buchan, 2005; Chen et al., 2009; Yoon, 2011b) or “subject norms” (Yoon, 2012, p. 576) also resemble social consensus, and therefore ethical judgments, in that these refer to respondent estimates of what other people think of as appropriate and thus would recommend to the respondents themselves in a situation with apparent ethical implications. Smith et al. (2007, p. 662, Note 10) also addressed conceptual “overlap between our measures of outcome expectancies and moral evaluations”, but the congruence addressed in that study seemed less complete than that noted here between social consensus and ethical judgments. Although some associations have been unexpectedly weak (Bateman et al., in press), observed strong relationships between ethical judgments and both perceived consensus (e.g., Barnett, 2001, $r=.67, .67$; Shaw, 2003, $r=.60, .48$; Valentine and Bateman, 2011, $r=.20$, intentions only; Valentine and Hollingsworth, 2012, $r=.34, .61$ ) and subjective norms (e.g., $r=.45$, Buchan, 2005; $r=$ -.26, -.40, Chen et al., 2009; $r=.55$, Cherry and Fraedrich, 2000; Yoon, 2011b) may have done little more than verify once again that different ethical judgments indicators tend to be strongly correlated (cf. Reidenbach and Robin, 1990).

Conclusion: Relationships between ethical judgments and respondent-determined social consensus seem not to be meaningful and may largely even be tautological, because individuals have agreed, for example, that an activity is culturally unacceptable (judgments) and also unacceptable in the wider society (consensus).

\section{Ethical Issue Recognition and Importance}

Individual perceptions or recognition of an ethical issue, or its importance (for example, as assessed by Barnett, 2001; Chan et al., 2008; Fleischman and Valentine, 2003; Haines et al., 2008; Robin et al., 1996; Rottig et al., 2011; Singhapakdi, 1999; Valentine and Barnett, 2007; Valentine and Bateman, 2011; Valentine and Fleischman, 2003; Valentine and Page, 2006), also seem susceptible to multiple causal interpretations. Although recognition is generally presumed to influence judgments, anyone who 
regarded an ethically questionable activity as inappropriate would, in order to respond consistently, logically be inclined to concur that they personally recognized the existence of an ethical issue or problem. It may not actually make sense to see an activity as unethical but then to disagree that it raises an ethical issue, or to regard it as relatively unimportant. Observed strong relationships perhaps seem less meaningful than generally presumed (e.g., Barnett, 2001, $r=-.36$, -..56; Bateman et al., in press, $r=.26$, intentions; Pan and Sparks, 2012, $r=.25$ (five studies); Rottig et al., 2011, $r=-.27$, -.51, -.46;

Singhapakdi, 1999, $r=$-..42, -.33, -.67, intentions; Singhapakdi, Vitell, and Franke, 1999, intentions; Valentine and Hollingsworth, 2012).

Parenthetically, a nomenclature issue that arises here involves researchers claiming to have addressed ethical issue recognition when actually measuring ethical judgments. For example, Sarwono and Armstrong (2001, p. 44) "measured the respondents level of awareness of an ethical problem in each scenario”, and Schepers (2003, p. 347) drew conclusions about “perception of an ethical problem”, but the survey items in both studies assessed judgments, and no separate "perceptions” measure was used. Conclusion: Definitive conclusions about the meaning and significance of observed relationships between ethical judgments and recognition/importance of an ethical issue seem elusive.

\section{Comparing Ethical Judgments in Different Groups}

Many investigations that have not related ethical judgments to various respondent characteristics (as discussed previously) have compared judgments scores in different groups of people (see Table 4). Often this is the only real purpose of studies, which tend to be purely exploratory, feature vague and difficult-to-interpret hypotheses that do not always specify precisely the expected differences between groups (e.g., both Americans and Russians will "rely on multiple moral philosophies in forming their intention to behave”, Beekun, Westerman, and Barghouti, 2005, Hypothesis 5; “Canadian accounting students use more post-conventional stage MES factors than Chinese accounting students when making auditing decisions”, Ge and Thomas, 2008, Hypothesis 4; “There are differences in the ethical intentions of business managers in the U.S. and Morocco”, Oumlil and Balloun, 2009, Hypothesis 5), and for which no empirical support emerges (e.g., Beekun et al., 2005, Hypotheses 1, 3; Beekun, Hamdy, Westerman, 
and HassabElnaby, 2008, Hypotheses 3, 4, 5; Cherry et al., 2003, Hypotheses 3, 4, 6, 7).

\section{INSERT TABLE 4 ABOUT HERE}

Conclusion: Different groups of respondents sometimes, but not always, differ in their judgments of the appropriateness of ethically questionable activities. More research is needed before any firm, or even tentative, conclusions can emerge regarding relevant differences between and among different groups. The summary provided in Table 4 may provide a useful starting point for this investigation.

\section{Ethical Judgments and Decisions/Recommended Solutions}

The more that insurance claim padding by policy holders was interpreted as ethically justified, the greater the recommended award that respondents believed that claimants should receive (Dean, 2004). The more that insider trading was viewed as ethically inappropriate, the more onerous the recommended sanctions against the offenders (Kaplan et al., 2009). The more that individuals interpreted corporate support for controversial social issues as inappropriate, the more likely they were to take some retaliatory action against the company (e.g., participate in a boycott; Swimberghe, Flurry, and Parker, 2011).

Conclusion: As with behavioral intentions, individuals react to the perceived ethical appropriateness of an action when forming conclusions about how best to respond to the action in question.

\section{Ethical Judgments in Different Versions of Vignettes}

As discussed, one approach to assess Jones's (1991) situational characteristics that might affect ethical judgments is to solicit respondent opinions. Another approach is to create multiple versions of vignettes in which specific characteristics explicitly differ in different versions. For example, one version of a vignette intended to differ in magnitude of consequences might involve receiving a valuable gift from a supplier while the gift in the other version was inexpensive. McMahon and Harvey (2007a) determined that, among individuals exposed to only one (Study 1, p. 344) or to both versions of vignettes (Study 2, p. 348), questionable actions were seen as more inappropriate when moral intensity was manipulated to be high rather than low. Respondents thus were inclined, for example, to regard accepting expensive jewelry as more inappropriate than accepting a paperback novel (McMahon and Harvey, 2006, p. 386), which may suggest little more than readers attended to vignette characteristics when forming ethical judgments 
and seem aware that trivial consequences are indeed trivial. One salient difference across 13 different versions of vignettes presented to each respondent was the monetary magnitude of consequences, and the greater the consequences, the more unethical activities were seen to be (Tsalikis et al., 2001, p. 241;

Tsalikis, Seaton, and Tomaras, 2002, p. 289). Cherry and Fraedrich (2002) created multiple versions of a bribery vignette that differed in the degree of personal risk associated with the bribery, which was viewed as more ethically inappropriate in the high-risk situation. Shafer (2002), however, determined that ethical judgments did not differ based on either the amount of the fraud or the level of risk involved. Schepers (2003) compared ethical judgments in different versions of vignettes that differed in expected profit, but results were opposite to those expected. Only minor differences emerged in respondent perceptions of probable magnitude of consequences, proximity, and social consensus when, in different versions of the same basic vignette, these were specifically manipulated to be objectively high and low (McMahon and Harvey, 2007a, Table 8). Although “objective” and “perceived” vignette characteristics "are likely to be strongly correlated” (Bay and Nikitkov, 2011, p. 5), this does not always seem to be the case.

Conclusion: The meaning and significance of differences in ethical judgments across multiple versions of vignettes designed to differ in specific situational characteristics is not obvious, especially in light of inconsistent connections between "objective” and "perceived” vignette characteristics. These results may, however, have essentially confirmed that respondents were able, at least sometimes, to understand vignette details as intended by researchers.

\section{DISCUSSION: SEARCHING FOR A WAY FORWARD}

At its core, the construct of ethical judgments seems both elegant and straightforward. To what extent is an ethically questionable activity interpreted as inappropriate, unethical, or simply wrong? In general, studies featuring the empirical assessment of ethical judgments do not mirror this essential simplicity. There has been little consensus about the appropriate label to attach to this construct (see Table 2), which seems likely to handicap potential investigators interested in reviewing relevant literature, and has apparently led to pervasive distortions and even inaccuracies when interpreting empirical findings and deriving conclusions from these (see Table 3). 
The approach taken in this paper has been to focus on the construct of ethical judgments as addressed by Reidenbach and Robin (1990) and its associated measure, the Multidimensional Ethics Scale (MES; see Table 1). Given the difficulties in identifying literature addressed earlier, we make no claims concerning the comprehensiveness of this paper's review. However, this review also had an unwavering concentration on what research investigations "actually found" (based on the construct assessed with ethical judgments measures) rather than what research reports frequently claimed to have found. Such claims all too often seem, at best, only tenuously connected with “actual findings” (see Table 3). Moreover, empirical results of much relevant research indeed seem mundane and trivial, and cast doubt on whether any appreciable advancement in understanding ethical judgments has occurred after almost a quarter century of study. As discussed throughout, ethical judgments relate consistently to few respondent characteristics or anything else. Research investigations verify repeatedly what has been known for decades, researchers frequently advance hypotheses that fail to garner empirical support, and patterns of results that emerge are often opposite to what was predicted (e.g., Barnett and Vaicys, 2000; Cherry and Fraedrich, 2000, Hypothesis 9a; Chiu and Erdener, 2003; Clark and Dawson, 1996; Fleischman and Valentine, 2003; Schepers, 2003; Shawver and Sennetti, 2009, results involving egoism). Something does not quite seem to “add up” here.

Perhaps there is something "wrong” with the measures used. Investigators often seem inclined to respond to a general absence of meaningful research findings by attempting to "fine-tune" the measures of ethical judgments and to create combinations of survey items that differ from those presented in the 1990 version of the MES (see Table 1; e.g., Hansen, 1992; Kujala, 2001; Kujala and Pietilainen, 2007; Kujala, Lamsa, and Penttila, 2011; McMahon and Harvey, 2007b). Researcher tendencies to report detailed results of factor analyses of ethical judgments survey items, or even to refer to such analyses in passing (e.g., Tansey, Hyman, and Brown, 1992; fifty relevant studies are identified in the list of references), also seemingly suggests an ongoing search for the "correct” item combinations or a "better" measure. Some scholars have advocated for the use of unique combinations of survey items for each vignette (e.g., “a scale must be constructed and validated for each application studied”, Cohen et al., 
1993, p. 25; see also Cohen et al., 2001; Schwepker, 1999). For example, the items “just”, “fair”, and “acceptable to my family” appeared in the same scale in one vignette used by Davis et al. (2001), were divided among two scales in a second vignette, and were omitted altogether from a third. Such procedures, however, inevitably make results difficult or even impossible to compare and contrast across different studies, or even across different vignettes in the same study, and may therefore actually serve to impede the advancement of knowledge.

Ethical judgments are inseparable from the context in which they occur and this notion must be integrated into research for knowledge to move forward. If the quest to find a "better measure" has not produced a breakthrough in understanding, then perhaps a different approach such as this one is required. Although seemingly easy to overlook, ethical judgments do not occur, and perhaps cannot meaningfully be examined, in isolation. Apparent research focus on the "format” of ethical judgments (which combination of survey items to use) has seemingly not been matched by a comparable focus on the “content” of such judgments (what actually is being judged). While consideration of some specific activity performed in a specific way is critical to a meaningful integration of context, it may not be possible to draw conclusions about "generalized ethical reasoning” (Valentine and Rittenburg, 2007, p. 127) based on the use of specific vignettes dealing with specific issues in specific ways (cf. Collins, 2000, p. 16). Moreover, it may not always be appropriate simply to aggregate across results from different vignettes within the same investigation, or different subscales of the Vitell and Muncy (1992) Consumer Ethics Scale, when drawing conclusions (procedures followed by Pan and Sparks, 2012) when these vignettes and subscales differ profoundly in terms of what actually is being judged.

This review also uncovered a heretofore largely overlooked, but potentially salient, reality: regardless of the complex models, sophisticated methodologies, detailed analyses, and apparent thoroughness in many published reports, researchers seldom provide concrete reasons for selecting vignettes (e.g., “vignettes were adopted from prior ethics research”, Cohen and Bennie, 2006, p. 16; see also Beekun et al., 2005, p. 240; Beekun et al., 2008, p. 593; Davis et al., 2001, p. 41; Eweje and Brunton, 2010, p. 100; Haines et al., 2008, p. 392; Lin and Ho, 2008, p. 1217; Marques and Azvedo-Pereira, 2009, 
p. 343; Patel, 2003, p. 79; Rottig et al., 2011, p. 174; Shawver and Sennetti, 2009). Typically, specific vignettes are employed because they were "used in another study”, generally "used in past research”, or have been "used successfully in some other context” (often, no reasons of any kind are mentioned).

Reidenbach and Robin (1988, 1990) adopted three of 14 vignettes of Dornoff and Tankersley (1975) that described marketing situations of ambiguous ethicality, but likewise did not indicate why they retained only these vignettes.

The activities being judged in relevant research have taken many different forms. These have included "whistle blowing" where respondents evaluate the appropriateness of a vignette protagonist disclosing others' questionable activities (e.g., Ayers and Kaplan, 2005; Barnett et al., 1994, Vignette 19; Barnett et al., 1996; Chiu, 2003; Chiu and Erdener, 2003; Hansen, 1992, Vignettes 2 and 3; Jung, 2009, Vignette 3; Radtke, 2000; Zhang et al., 2009a,b), laying off an employee (e.g., Cohen et al., 1998, Vignette 5; Shawver and Sennetti, 2009; Valentine and Hollingsworth, 2012), paying for inside information (e.g., Valentine and Rittenburg, 1994), bribery (e.g., Valentine and Rittenburg, 2004), software piracy (e.g., Wagner and Sanders, 2001), and behavior in the face of threats or pressure from superiors or clients (e.g., managers explicitly ordering vignette protagonists to engage in bribery and price-fixing, Smith et al., 2007; see also Barnett et al., 1994, Vignettes 3 and 18; Cohen et al., 1998, Vignette 4; Cruz, Shafer, and Strauser, 2000; Flory et al., 1992; Loo, 2004; Marques and AzevedoPereira, 2009, Vignettes 1 and 5; Patel, 1993, Vignettes 1 and 2; Shawver and Sennetti, 2009). Some vignettes involve activities that create no apparent harms of any kind and thus seem not to be ethically questionable at all, such as consumers bringing their own shopping bags to stores (Chan et al., 2008), customers applying for credit cards but rarely using them (Ding et al., 2009), refunding money to customers (Dornoff and Tankersley, 1975), extending credit or loans that violate only the lenders' “normal (internal) lending criteria” (e.g., Flory et al., 1992; Cohen et al., 1998, Vignette 2; Shawver and Sennetti, 2009), and hiring Hispanic persons for a Mexican restaurant (Schepers, 2003).

Although even this sampling of vignette content may seem overwhelming in its diversity, perhaps a finite set of common themes exist in vignettes that, once identified, might provide greater opportunities 
for more focused research. Such research has the potential to produce more consistent results and thus enable generalizable conclusions to emerge. As discussed, ethical idealism seems associated with regarding most questionable activities as wrong, but also with interpreting whistle blowing as entirely appropriate. Ethical relativists may also approve of whistle blowing, but are inclined, weakly, to regard many dubious activities as ethically acceptable. By building on the foundation of such findings, and by carefully choosing specific vignettes based on clear conceptual reasons (e.g., the specific theme addressed), future investigation may uncover more meaningful results than have heretofore emerged. Obviously, important questions remain to be resolved in coming to grips with possible vignette themes. For example, is a vignette's subject matter the critical detail in theme identification (e.g., all vignettes involving bribery should be categorized together, with vignettes involving price fixing placed in a different category), or is it how these activities occur that is salient? Vignette protagonists may take it upon themselves to offer bribes or fix prices. Bribes could be demanded of protagonists, or erstwhile competitors could insist that prices be agreed upon in advance. Supervisors could order or "suggest” that protagonists pay bribes or fix prices. Are these differing circumstances equivalent, or are they separate and distinct? Is it realistic to ask respondents to evaluate only the ethics of a protagonist following orders and not to judge those of the supervisor who issued orders or, say, the bribe recipient who demanded payment? The absence of predicted findings in Shafer (2002) occurred in the context of a vignette in which an accountant was ordered to backdate sales invoices and "was concerned about losing his job if he refused to comply” (p. 259). Thus, the accountant had limited discretion to behave as he might otherwise choose and did not appear to benefit personally from the actions described, beyond maintaining the status quo. Another noteworthy characteristic of this vignette was the absence of any reference to potential victims; that is, anyone harmed by backdating sales invoices. Such a vignette appears to differ profoundly from those used by Reidenbach and Robin $(1988,1990)$ that featured what appeared to be complete freedom on the part of protagonists to behave as they did (e.g., by stalling until the warranty expired before repairing a customer’s problem vehicle, an auto dealer was able to extract a higher payment from the customer than would otherwise have been earned), personal benefit to protagonists 
(e.g., more money), and high victim salience (e.g., explicit reference to a customer required to pay extra money). Perhaps participants who evaluated the actions of the accountant (Shafer, 2002) had not been asked to judge the behavior of the most salient protagonist. The potential significance of vignette details such as protagonist “degrees of freedom”, the extent of personal benefits accruing to protagonists, and victim salience awaits further inquiry. In the meantime, we recommend that investigators at least be mindful of such details in vignette selection, as these may provide a path forward toward a deeper and more meaningful understanding of ethical judgments. 


\section{NOTE}

Negatively signed relationships occurred here when the direction of scoring was reversed for either judgments or intentions. For example, in the Barnett and Valentine (2004) study, higher “judgments” scores implied stronger beliefs that questionable actions were unethical and higher “intentions" scores suggested greater tendencies to behave similarly (p. 342). Persons who regarded the activities as wrong (high judgments scorers) thus tended to score low on intentions. Although negatively signed correlations should perhaps be avoided here because of potential confusion that might arise, Barnett and Valentine (2004) were nonetheless unambiguously clear about the precise interpretations of high and low scores. Not all papers reviewed matched this level of clarity. For example, higher scores on ethical judgments have "represented items that are less consistent with the underlying philosophy” (Cruz et al., 2000, p. 228), “a high level of individual moral values” (Herndon et al., 2001, p. 76), “lower ethicality” (Rittenburg and Valentine, 2002, p. 297), "higher agreement toward business problems perceived with ethical dilemma” (Sarwono and Armstrong, 2001, p. 45), "higher moral value judgment” (Schwepker, 1999, p. 306), and "greater generalized ethicality” (Valentine and Fleischman, 2003, p. 331). Does greater “consistency” or higher "agreement” suggest that high scorers viewed the activities as more or less appropriate than low scorers? Does "lower ethicality" refer to the action depicted in the vignette or to the respondents themselves? Any ambiguity here makes results more difficult to interpret than they might otherwise be and likely need to be. For example, Pan and Sparks (2012, p. 86) stated that, contrary to the general pattern of results from most studies, “Conversely, Barnett (2001) reports a negative relationship between ethical awareness and judgments”. When discussing the ethical judgments measure, however, Barnett (2001) did not specify the precise meaning of high or low scores (pp. 1044-1045), but did reveal (p. 1048) that "recognizing an issue as having a moral component was associated with judgments that the actions were, indeed, unethical”, which suggests that a low score on ethical judgments meant that respondents viewed the activity as inappropriate. In effect, this negative relationship was consistent with positive relationships from other studies, but did not appear to be interpreted as such. 


\section{References}

Ayers, S. and S. E. Kaplan: 2005, 'Wrongdoing by Consultants: An Examination of Employees'

Reporting Intentions', Journal of Business Ethics 57, 121-137. (H)

*Babin, B. J. and L. A. Babin: 1996, 'Effects of Moral Cognitions and Customer Emotions on Shoplifting Intentions', Psychology and Marketing 13, 785-803. (R)

*Babin, B. J., M. Griffin and J. S. Boles: 2004, 'Buyer Reactions to Ethical Beliefs in the Retail

Environment', Journal of Business Research 57, 1155-1163.

Bailey, W. and A. Spicer: 2007, 'When Does national Identity Matter? Convergence and Divergence in International Business Ethics', Academy of Management Journal 50, 1462-1480.

Barnett, T.: 2001, 'Dimensions of Moral Intensity and Ethical Decision Making: An Empirical Study', Journal of Applied Social Psychology 31, 1038-1057.

Barnett, T., K. Bass and G. Brown: 1994, 'Ethical Ideology and Ethical Judgment Regarding Ethical Issues in Business', Journal of Business Ethics 13, 469-480.

Barnett, T., K. Bass and G. Brown: 1996, 'Religiosity, Ethical Ideology, and Intentions to Report a Peer’s Wrongdoing', Journal of Business Ethics 15, 1161-1174.

Barnett, T., K. Bass, G. Brown and F. J. Hebert: 1998, 'Ethical Ideology and the Ethical Judgments of Marketing Professionals', Journal of Business Ethics 17, 715-723.

Barnett, T., G. Brown and K. Bass: 1994, 'The Ethical Judgments of College Students Regarding Business Issues', Journal of Education for Business 69, 333-338.

Barnett, T. and C. Vaicys: 2000, 'The Moderating Effect of Individuals’ Perceptions of Ethical Work Climate on Ethical Judgments and Behavioral Intentions', Journal of Business Ethics 27, 351-362.

Barnett, T. and S. Valentine: 2004, 'Issue Contingencies and Marketers' Recognition of Ethical Issues, Ethical Judgments and Behavioral Intentions', Journal of Business Research 57, 338-346.

Bass, K., T. Barnett and G. Brown: 1999, 'Individual Difference Variables, Ethical Judgments, and Ethical Behavioral Intentions', Business Ethics Quarterly 9, 183-205. (H) 
Bateman, C. R., J. P. Fraedrich and R. Iyer: 2003, 'The Integration and Testing of the Janus-Headed Model within Marketing', Journal of Business Research 56, 587-596.

Bateman, C. R., S. Valentine and T. Rittenburg: in press, 'Ethical Decision Making in a Peer-to-Peer File Sharing Situation: The Role of Moral Absolutes and Social Consensus', Journal of Business Ethics.

Bay, D. and A. Nikitkov: 2011, 'Subjective Probability Assessments of the Incidence of Unethical Behavior: The Importance of Scenario-Respondent Fit', Business Ethics: A European Review 20, 1-11.

Beekun, R. I., R. Hamdy, J. W. Westerman and H. R. HassabElnaby: 2008, 'An Exploration of Ethical Decision-Making Processes in the United States and Egypt', Journal of Business Ethics 82, 587-605.

Beekun, R. I., Y. Stedham, J. W. Westerman and J. H. Yamamura: 2010, 'Effects of Justice and Utilitarianism on Ethical Decision Making: A Cross-Cultural Examination of Gender Similarities and Differences', Business Ethics: A European Review 19, 309-325.

Beekun, R. I., Y. Stedham, J. H. Yamamura and J. A. Barghouti: 2003, 'Comparing Business Ethics in Russia and the U.S.', International Journal of Human Resource Management 14, 1333-1349.

Beekun, R. I., Y. Stedham and J. H. Yamamura: 2003, 'Business Ethics in Brazil and the U.S.: A Comparative Investigation', Journal of Business Ethics 42, 267-279.

Beekun, R. I., J. Westerman and J. Barghouti: 2005, 'Utility of Ethical Frameworks in Determining Behavioral Intention: A Comparison of the U.S. and Russia', Journal of Business Ethics 61, 235-247. Boyle, B. A.: 2000, 'The Impact of Customer Characteristics and Moral Philosophies on Ethical Judgments of Salespeople', Journal of Business Ethics 23, 249-267.

Brunton, M. and G. Eweje: 2010, 'The Influence of Culture on Ethical Perception Held by Business Students in a New Zealand University', Business Ethics: A European Review 19, 349-362. (R)

*Buchan, H. F.: 2005, 'Ethical Decision Making in the Public Accounting Profession: An Extension of Ajzen’s Theory of Planned Behavior', Journal of Business Ethics 61, 165-181. (H)

Bucar, B., M. Glas and R. D. Hisrich: 2003, 'Ethics and Entrepreneurs: An International Comparative Study', Journal of Business Venturing 18, 261-281. 
Carroll, A. B. and A. K. Buchholtz: 2012, Business and Society: Ethics. Sustainability, and Stakeholder Management, 8th edition (South-Western, Mason, OH).

Chan, R. Y. K., Y. H. Wong and T. K. P. Leung: 2008, 'Applying Ethical Concepts to the Study of “Green” Consumer Behavior: An Analysis of Chinese Consumers’ Intentions to Bring their Own Shopping Bags', Journal of Business Ethics 79, 469-481. (H)

Chen, M. F., C. T. Pan and M. C. Pan: 2009, 'The Joint Moderating Impact of Moral Intensity and Moral Judgment on Consumer's Use Intention of Pirated Software', Journal of Business Ethics 90, 361-373. (H) Cherry, J.: 2006, 'The Impact of Normative Influence and Locus of Control on Ethical Judgments and Intentions: A Cross-Cultural Comparison', Journal of Business Ethics 68, 113-132.

Cherry, J., and J. Fraedrich: 2000, 'An Empirical Investigation of Locus of Control and the Structure of Moral Reasoning: Examining the Ethical Decision-Making Processes of Sales Managers', Journal of Personal Selling and Sales Management 20, 173-188.

Cherry, J. and J. Fraedrich: 2002, 'Perceived Risk, Moral Philosophy and Marketing Ethics: Mediating Influences on Sales Managers’ Ethical Decision-Making', Journal of Business Research 55, 951-962. Cherry, J., M. Lee and C. S. Chien: 2003, 'A Cross-Cultural Application of a Theoretical Model of Business Ethics: Bridging the Gap between Theory and Data', Journal of Business Ethics 44, 359-376.

Chiu, R. K.: 2003, 'Ethical Judgment and Whistleblowing Intention: Examining the Moderating Role of Locus of Control', Journal of Business Ethics 43, 65-74. (H)

Chiu, R. K. and C. B. Erdener: 2003, 'The Ethics of Peer Reporting in Chinese Societies: Evidence from Hong Kong and Shanghai', International Journal of Human Resource Management 14, 335-353. (H)

Christie, R. and F. L. Geis: 1970, Studies in Machiavellianism, (Academic Press, New York).

*Clark, J. W. and L. E. Dawson: 1996, 'Personal Religiousness and Ethical Judgments: An Empirical Analysis', Journal of Business Ethics 15, 359-372.

Cohen, J. R. and N. M. Bennie: 2006, 'The Applicability of a Contingent Factors Model to Accounting Ethics Research', Journal of Business Ethics 68, 1-18. 
*Cohen, J., L. Pant and D. Sharp: 1993, 'A Validation and Extension of a Multidimensional Ethics Scale', Journal of Business Ethics 12, 13-26. (R)

Cohen, J. R., L. W. Pant and D. J. Sharp: 1995, 'An Exploratory Examination of International Differences in Auditors' Ethical Perceptions', Behavioral Research in Accounting 7, 37-64. (R)

Cohen, J. R., L. W. Pant and D. J. Sharp: 1996, 'Measuring the Ethical Awareness and Ethical Orientation of Canadian Auditors', Behavioral Research in Accounting 8 (supp.), 98-119. (R)

*Cohen, J. R., L. W. Pant and D. J. Sharp: 1998, 'The Effect of Gender and Academic Discipline Diversity on the Ethical Evaluations, Ethical Intentions and Ethical Orientation of Potential Public Accounting Recruits', Accounting Horizons 12, 250-270.

*Cohen, J. R., L. W. Pant and D. J. Sharp: 2001, 'An Examination of Differences in Ethical DecisionMaking between Canadian Business Students and Accounting Professionals', Journal of Business Ethics 30, 319-336. (R)

Cole, B. C. and D. L. Smith: 1996, 'Perceptions of Business Ethics: Students vs. Business People', Journal of Business Ethics 15, 889-896.

Collins, D.: 2000, 'The Quest to Improve the Human Condition: The First 1500 Articles Published in Journal of Business Ethics', Journal of Business Ethics 26, 1-73.

*Cruz, C. A., W. E. Shafer and J. R. Strauser: 2000, 'A Multidimensional Analysis of Tax Practitioners' Ethical Judgments', Journal of Business Ethics 24, 223-244. (R)

Dabholkar, P. A. and J. J. Kellaris: 1992, 'Toward Understanding Marketing Students’ Ethical Judgment of Controversial Selling Practices', Journal of Business Research 24, 313-329.

*Davis, M. A., M. G. Andersen and M. B. Curtis: 2001, 'Measuring Ethical Ideology in Business Ethics: A Critical Analysis of the Ethics Position Questionnaire', Journal of Business Ethics 32, 35-53.

Dean, D. H.: 2004, 'Perceptions of the Ethicality of Consumer Insurance Claim Fraud', Journal of Business Ethics 54, 67-79.

Ding, C. G., K. Chang and N. T. Liu: 2009, 'The Roles of Personality and General Ethical Judgments in Intention to Not Repay Credit Card Expenses', Service Industries Journal 29, 813-834. 
Dornoff, R. J. and C. B. Tankersley: 1975, 'Perceptual Differences in Market Transactions: A Source of Consumer Frustration', Journal of Consumer Affairs 97, 97-103.

Dubinsky, A. J., R. Nataraajan and W. Y. Huang: 2004, 'The Influence of Moral Philosophy on Retail Salespeoples’ Ethical Perceptions', Journal of Consumer Affairs 38, 297-319.

Dunfee, T. W.: 2006, 'A Critical Perspective of Integrative Social Contracts Theory: Recurring Criticisms and Next Generation Research Topics', Journal of Business Ethics 68, 303-328.

Duska, R.: 1996, 'Ethics, Law, and the Social Sciences: Reflections on Robin, King, and Reidenbach', American Business Law Journal 34, 301-316.

Eastman, J. K., K. L. Eastman and M. A. Tolson: 2001, 'The Relationship between Ethical Ideology and Ethical Behavioral Intentions: An Exploratory Look at Physicians' Responses to Managed Case Dilemmas', Journal of Business Ethics 31, 209-224.

*Ellis, T. S. and D. Griffith: 2001, 'The Evaluation of IT Ethical Scenarios Using a Multidimensional Scale', The Data Base for Advances in Information Systems 32, 75-84. (R)

Emerson, T. L. N., S. J. Conroy and C. W. Stanley: 2007, 'Ethical Attitudes of Accountants: Recent Evidence from a Practitioners’ Survey', Journal of Business Ethics 71, 73-87.

Eweje, G., and M. Brunton: 2010, 'Ethical Perceptions of Business Students in a New Zealand University: Do Gender, Age, and Work Experience Matter?', Business Ethics: A European Review 19, 95-111. Eynon, G., N. Y. Hill and K. T. Stevens: 1997, 'Factors that Influence the Moral Reasoning Abilities of Accountants: Implications for Universities and the Profession', Journal of Business Ethics 16, 1297-1309. Fennell, D. A. and D. C. Malloy: 1999, 'Measuring the Ethical Nature of Tourism Operators', Annals of Tourism Research 26, 928-943.

Fleischman, G. and S. Valentine: 2003, 'Professionals’ Tax Liability Assessments and Ethical Evaluations in an Equitable Relief Innocent Spouse Case', Journal of Business Ethics 42, 27-44.

*Flory, S. M., T. J. Phillips, Jr., R. E. Reidenbach and D. P. Robin: 1992, 'A Multidimensional Analysis of Selected Ethical Issues in Accounting', Accounting Review 67, 284-302. (R) 
Flory, S. M., T. J. Phillips, Jr., R. E. Reidenbach and D. P. Robin: 1993, 'A Reply to “A Comment on a Multidimensional Analysis of Selected Ethical Issues in Accounting’”, Accounting Review 68, 417-421. Forsyth, D. R.: 1980: 'A Taxonomy of Ethical Ideologies', Journal of Personality and Social Psychology 39, 175-184.

Froelich, K.S. and J. L. Kottke: 1991, 'Measuring Individual Beliefs about Organizational Ethics', Educational and Psychological Measurement 51, 377-383.

*Haines, R., M. D. Street and D. Haines: 2008, 'The Influence of Perceived Importance of an Ethical Issue on Moral Judgment, Moral Obligation, and Moral Intent', Journal of Business Ethics 81, 387-399. *Hansen, R. S.: 1992, 'A Multidimensional Scale for Measuring Business Ethics: A Purification and a Refinement', Journal of Business Ethics 11, 523-534.

Hebert, F. J., K. E. Bass and J. Tomkiewicz: 2002, 'Ethics in Family vs. Nonfamily Owned Businesses', Psychological Reports 91, 952-954.

*Henderson, B. C. and S. E. Kaplan: 2005, 'An Examination of the Role of Ethics in Tax Compliance Decisions', Journal of the American Taxation Association 27, 39-72. (H)

Henthorne, T. L. and M. S. LaTour: 1995, 'A Model to Explore the Ethics of Erotic Stimuli in Print Advertising', Journal of Business Ethics 14, 561-569.

Henthorne, T. L., D. P. Robin and R. E. Reidenbach: 1992, 'Identifying the Gaps in Ethical Perceptions between Managers and Salespersons: A Multidimensional Approach', Journal of Business Ethics 11, 849856.

Herndon, N. C., Jr., J. P. Fraedrich and Q. J. Yeh: 2001, 'An Investigation of Moral Values and the Ethical Content of Corporate Culture: Taiwanese versus US Sales People', Journal of Business Ethics 30, 73-85.

Hsu, Y. H., W. Fang and Y. Lee: 2009, 'Ethically Questionable Behavior in Sales Representatives-- An Example from the Taiwanese Pharmaceutical Industry', Journal of Business Ethics 88, 155-166.

Huang, C. Y.: 2005, 'File Sharing as a Form of Music Consumption', International Journal of Electronic Commerce 9, 37-55. 
Hudson, S.: 2007, 'To Go or Not to Go? Ethical Perspectives on Tourism in an “Outpost of Tyranny”', Journal of Business Ethics 76, 385-396.

Hudson, S., D. Hudson and J. Peloza: 2008, 'Meet the Parents: A Parents’ Perspective on Product Placement in Children's Films', Journal of Business Ethics 80, 289-304.

Hudson, S. and G. Miller: 2005, 'Ethical Orientation and Awareness of Tourism Students', Journal of Business Ethics 62, 383-396.

Humphreys, N., D. P. Robin, R. E. Reidenbach and D. L. Moak: 1993, 'The Ethical Decision Making Process of Small Business Owner/Managers and their Customers', Journal of Small Business

Management 31, 9-22. (R)

Hunt, S. D. and A. Z. Vasquez-Parraga: 1993, 'Organizational Consequences, Marketing Ethics, and Salesforce Supervision', Journal of Marketing Research 30(1), 78-90.

Jones, J. L. and K. L. Middleton: 2007, 'Ethical Decision-Making by Consumers: The Roles of Product Harm and Consumer Vulnerability', Journal of Business Ethics 70, 247-264.

Jones, T. M.: 1991, 'Ethical Decision Making by Individuals in Organizations: An Issue-Contingent Model', Academy of Management Review 16, 366-395.

Jones, W.A., Jr.: 1990, 'Student Views of “Ethical” Issues: A Situational Analysis', Journal of Business Ethics 9, 201-205.

*Jung, I.: 2009, 'Ethical Judgments and Behaviors: Applying a Multidimensional Ethics Scale to Measuring ICT Ethics of College Students', Computers and Education 53, 940-949. (R/H)

Kaplan, S. E., J. A. Samuels and L. Thorne: 2009, 'Ethical Norms of CFO Insider Trading', Journal of Accounting and Public Policy 28, 386-400.

Kaynama, S. A., A. King and L. W. Smith: 1996, 'The Impact of a Shift in Organizational Role on Ethical Perceptions: A Comparative Study', Journal of Business Ethics 15, 581-590.

*Klein, J. G. and N. C. Smith: 2004, 'Forewarning and Debriefing as Remedies to Deception in Consumer Research', Advances in Consumer Research 31, 759-765. 
*Kleiser, S. B., E. Sivadas, J. J. Kellaris and R. F. Dahlstrom: 2003, 'Ethical Ideologies: Efficient Assessment and Influence on Ethical Judgments of Marketing Practices', Psychology and Marketing 20, $1-21$.

Knotts, T. L., T. B. Lopez and H. I. Mesak: 2000, 'Ethical Judgments of College Students: An Empirical Analysis', Journal of Education for Business 75, 158-163.

Kohlberg, L.: 1976, 'Moral Stages and Moralization: The Cognitive-Developmental Approach', In T.

Lickona (Ed.), Moral Development and Behavior (Holt, Rinehart and Winston, New York), pp. 31-53.

*Kujala, J.: 2001, 'A Multidimensional Approach to Finnish Managers’ Moral Decision-Making', Journal of Business Ethics 34, 231-254.

*Kujala, J., A. M. Lamsa and K. Penttila: 2011, 'Managers' Moral Decision-Making Patterns over Time: A Multidimensional Approach', Journal of Business Ethics 100, 191-207.

*Kujala, J. and T. Pietilainen: 2007, 'Female Managers' Ethical Decision-Making: A Multidimensional Approach', Journal of Business Ethics 53, 153-163.

*LaFleur, E. K., R. E. Reidenbach, D. P. Robin and P. J. Forrest: 1996, 'An Exploration of Rule Configuration Effects on the Ethical Decision Processes of Advertising Professionals', Journal of the Academy of Marketing Science 24(1), 66-76.

*Landeros, R. and R. E. Plank: 1996, 'How Ethical are Purchasing Management Professionals?', Journal of Business Ethics 15, 789-803.

Larkin, J. M.: 2000, 'The Ability of Internal Auditors to Identify Ethical Dilemmas', Journal of Business Ethics 23, 401-409.

Latif, D. A.: 2000, 'Ethical Cognition and Selection-Socialization in Retail Pharmacy', Journal of Business Ethics 25, 343-357.

*LaTour, M. S. and T. L. Henthorne: 1994, 'Ethical Judgments of Sexual Appeals in Print Advertising', Journal of Advertising 23(3), 81-90.

LaTour, M. S., R. L. Snipes and S. J. Bliss: 1996, 'Don’t Be Afraid to Use Fear Appeals: An Experimental Study', Journal of Advertising Research 36(2), 59-67. 
*Lin, C. Y. and Y. H. Ho: 2008, 'An Examination of Cultural Differences in Ethical Decision Making Using the Multidimensional Ethics Scale', Social Behavior and Personality 36, 1213-1222. (R)

Loo, R.: 2001, 'Encouraging Classroom Discussion of Ethical Dilemmas in Research Management: Three Vignettes', Teaching Business Ethics 5, 195-212.

Loo, R.: 2002, 'Tackling Ethical Dilemmas in Project Management Using Vignettes', International Journal of Project Management 20, 489-495.

*Loo, R.: 2004, 'Support for Reidenbach and Robin’s (1990) Eight-Item Multidimensional Ethics Scale', Social Science Journal 41, 289-294.

Marques, P. A. and J. Azevedo-Pereira: 2009, 'Ethical Ideology and Ethical Judgments in the Portugese Accounting Profession', Journal of Business Ethics 86, 227-242.

McDonald, G.: 2000, 'Cross-Cultural Methodological Issues in Ethical Research', Journal of Business Ethics 27, 89-104.

McDonald, G. and P. C. Pak: 1996, 'It's All Fair in Love, War, and Business: Cognitive Philosophies in Ethical Decision Making', Journal of Business Ethics 15, 973-996.

McMahon, J. M. and R. Cohen: 2009, 'Lost in Cyberspace: Ethical Decision Making in the Online Environment', Ethics and Information Technology 11, 1-17.

*McMahon, J. M. and R. J. Harvey: 2006, 'An Analysis of the Factor Structure of Jones’ Moral Intensity Construct', Journal of Business Ethics 64, 381-404.

*McMahon, J. M. and R. J. Harvey: 2007a, 'The Effect of Moral Intensity on Ethical Judgment', Journal of Business Ethics 72, 335-357.

*McMahon, J. M. and R. J. Harvey: 2007b, 'Psychometric Properties of the Reidenbach-Robin Multidimensional Ethics Scale', Journal of Business Ethics 72, 27-39.

*Mittal, B. and W. M. Lassar: 2000, 'Sexual Liberalism as a Determinant of Consumer Response to Sex in Advertising', Journal of Business and Psychology 15, 111-127.

Mudrack, P. E., J. M. Bloodgood and W. H. Turnley: 2012, 'Some Ethical Implications of Individual Competitiveness', Journal of Business Ethics 108, 347-359. 
Mudrack, P. E. and E. S. Mason: 2010, 'The Asceticism Dimension of the Protestant Work Ethic:

Shedding its Status of Invisibility', Journal of Applied Social Psychology 40, 2043-2070.

*Nguyen, N. T., M. T. Basuray, W. P. Smith, D. Kopka and D. McCulloh: 2008, 'Moral Issues and Gender Differences in Ethical Judgment Using Reidenbach and Robin’s (1990) Multidimensional Ethics Scale: Implications in Teaching of Business Ethics', Journal of Business Ethics 77, 417-430.

*Nguyen, N. T. and M. D. Biderman: 2008, 'Studying Ethical Judgments and Behavioral Intentions Using Structural Equations: Evidence from the Multidimensional Ethics Scale', Journal of Business Ethics 83, 627-640. (H)

O'Fallon, M. J. and K. D. Butterfield: 2005, 'A Review of the Empirical Ethical Decision-Making Literature: 1996-2003', Journal of Business Ethics 59, 375-413.

Oumlil, A. B. and J. L. Balloun: 2009, 'Ethical Decision-Making Differences between American and Moroccan Managers', Journal of Business Ethics 84, 457-478.

*Palau, S. L.: 2001, 'Ethical Evaluations, Intentions, and Orientations of Accountants: Evidence from a Cross-Cultural Examination', International Advances in Economic Research 7, 351-364. (R)

Pan, Y. and J. R. Sparks: 2012, 'Predictors, Consequence, and Measurement of Ethical Judgments:

Review and Meta-Analysis', Journal of Business Research 65, 84-91. (H)

Patel, C.: 2003, 'Some Cross-Cultural Evidence on Whistle-Blowing as an Internal Control Mechanism', Journal of International Accounting Research 2, 69-96. (R)

Radtke, R. R.: 2000, 'The Effects of Gender and Setting on Accountants’ Ethically Sensitive Situations', Journal of Business Ethics 24, 299-312.

Rallapalli, K. C., S. J. Vitell and J. H. Barnes: 1998, 'The Influence of Norms on Ethical Judgments and Intentions: An Empirical Study of Marketing Professionals', Journal of Business Research 43, 157-168. (H)

*Razzaque, M. A. and T. P. Hwee: 2002, 'Ethics and Purchasing Dilemma: A Singaporean View', Journal of Business Ethics 35, 307-326. 
Reichert, T., M. S. LaTour and J. B. Ford: 2011, 'The Naked Truth: Revealing the Affinity for Graphic Sexual Appeals in Advertising', Journal of Advertising Research 51, 436-448.

Reidenbach, R. E. and D. P. Robin: 1988, 'Some Initial Steps toward Improving the Measurement of Ethical Evaluations of Marketing Activities', Journal of Business Ethics 7, 871-879.

Reidenbach, R. E. and D. P. Robin: 1990, 'Toward the Development of a Multidimensional Scale for Improving Evaluations of Business Ethics', Journal of Business Ethics 9, 639-653.

Reidenbach, R. E., D. P. Robin and L. Dawson: 1991, 'An Application and Extension of a Multidimensional Ethics Scale to Selected Marketing Practices and Marketing Groups', Journal of the Academy of Marketing Science 19, 83-92. (R)

Rest, J.R.: 1979, Development in Judging Moral Issues, (University of Minnesota Press, Minneapolis). Rest, J.R.: 1986, Moral Development: Advances in Theory and Research, (Praeger, New York).

*Rittenburg, T. L. and S. R. Valentine: 2002, 'Spanish and American Executives’ Ethical Judgments and Intentions', Journal of Business Ethics 38, 291-306.

Robin, D. P., G. Gordon, C. Jordan and R. E. Reidenbach: 1996, 'The Empirical Performance of Cognitive Moral Development in Predicting Behavioral Intent', Business Ethics Quarterly 6, 493-515. Robin, D. P., R. E. Reidenbach and B. J. Babin: 1997, 'The Nature, Measurement, and Stability of Ethical Judgments in the Workplace', Psychological Reports 80, 563-580.

*Robin, D. P., R. E. Reidenbach and P. J. Forrest: 1996, 'The Perceived Importance of an Ethical Issue as an Influence on the Ethical Decision-Making of Ad Managers', Journal of Business Research 35, 17-28. Robin, D. P., E. W. King and R. E. Reidenbach: 1996, 'The Effect of Attorneys' Perceived Duty to Client on their Ethical Decision Making Process' American Business Law Journal 34, 277-299.

Rottig, D., X. Koufteros and E. Umphress: 2011, 'Formal Infrastructure and Ethical Decision Making: An Empirical Investigation and Implications for Supply Management', Decision Sciences 42, 163-204. (H)

Sarwono, S. S. and R. W. Armstrong: 2001, 'Microcultural Differences and Perceived Ethical Problems: An International Business Perspective', Journal of Business Ethics 30, 41-56. 
*Schepers, D. H.: 2003, 'Machiavellianism, Profit, and the Dimensions of Ethical Judgment: A Study of Impact', Journal of Business Ethics 42, 339-352. (R)

Schmidt, C. D., C. R. McAdams and V. Foster: 2009, 'Promoting the Moral Reasoning of Undergraduate Business Students through a Deliberate Psychological Education-Based Classroom Intervention', Journal of Moral Education 38, 315-334.

*Schwepker, C. H., Jr.: 1999, 'Understanding Salespeople’s Intention to Behave Unethically: The Effects of Perceived Competitive Intensity, Cognitive Moral Development and Moral Judgment', Journal of Business Ethics 21, 303-316. (R)

Schwepker, C. H., Jr., O. C. Farrell and T. N. Ingram: 1997, 'The Influence of Ethical Climate and Ethical Conflict on Role Stress in the Sales Force', Journal of the Academy of Marketing Science 25, 99-108.

Schwepker, C. H. and D. J. Good: 2011, 'Moral Judgment and its Impact on Business-to-Business Sales Performance and Customer Relationships', Journal of Business Ethics 98, 609-625.

*Schwepker, C. H., Jr., and T. N. Ingram: 1996, 'Improving Sales Performance through Ethics: The Relationship between Salesperson Moral Judgment and Job Performance', Journal of Business Ethics 15, 1151-1160.

Shafer, W. E.: 2002, 'Effects of Materiality, Risk, and Ethical Perceptions on Fraudulent Reporting by Financial Executives', Journal of Business Ethics 38, 243-262.

*Shafer, W. E.: 2008, 'Ethical Climate in Chinese CPA Firms', Accounting, Organizations and Society 33, 825-835.

Shafer, W. E. and Simmons, R. S.: 2008, 'Social Responsibility, Machiavellianism and Tax Avoidance', Accounting, Auditing and Accountability Journal 21, 695-720. (H)

*Shaw, T. R.: 2003, 'The Moral Intensity of Privacy: An Empirical Study of Webmasters’ Attitudes, Journal of Business Ethics 46, 301-318.

Shawver, T. J. and L. H. Clements: 2007, 'The Intention of Accounting Students to Whistleblow in Situations of Questionable Ethical Dilemmas', Research on Professional Responsibility and Ethics in Accounting 11, 177-191. (R/H) 
Shawver, T. J. and J. T. Sennetti: 2009, 'Measuring Ethical Sensitivity and Evaluation', Journal of Business Ethics 88, 663-678. (H)

*Simpson, P. M., G. Brown and R. E. Widing II: 1998, 'The Association of Ethical Judgment of Advertising and Selected Advertising Effectiveness Response Variables', Journal of Business Ethics 17, 125-136.

Singh, J. J., S. J. Vitell, J. Al-Khatib and I. Clark III: 2007, 'The Role of Moral Intensity and Personal Moral Philosophies in the Ethical Decision Making of Marketers: A Cross-Cultural Comparison of China and the United States', Journal of International Marketing 15, 86-112. (H)

Singhapakdi, A.: 1999, 'Perceived Importance of Ethics and Ethical Decisions in Marketing', Journal of Business Research 45, 89-99.

Singhapakdi, A., S. J. Vitell and G. R. Franke: 1999, 'Antecedents, Consequences, and Mediating Effects of Perceived Moral Intensity and Personal Moral Philosophies', Journal of the Academy of Marketing Science 27, 19-36.

Smith, N. C. and E. Cooper-Martin: 1997, 'Ethics and Target Marketing: The Role of Product Harm and Consumer Vulnerability', Journal of Marketing 61(3), 1-20.

*Smith, N. C., S. S. Simpson and C. Y. Huang: 2007, 'Why Managers Fail to Do the Right Thing: An Empirical Study of Unethical and Illegal Conduct', Business Ethics Quarterly 17, 633-667. (H) *Snipes, R. L., M. S. LaTour and S. J. Bliss: 1999, 'A Model of the Effects of Self-Efficacy on the Perceived Ethicality and Performance of Fear Appeals in Advertising', Journal of Business Ethics 19, 273-285.

Sparks, J. R. and Y. Pan: 2010, 'Ethical Judgments in Business Ethics Research: Definition, and Research Agenda', Journal of Business Ethics 91, 405-418.

Spicer, A., T. W. Dunfee and W. J. Bailey: 2004, 'Does National Context Matter in Ethical Decision Making? An Empirical Test of Integrative Social Contracts Theory', Academy of Management Journal 47, 610-620. 
Staw, B. M.: 1975, 'Attribution of the “Causes” of Performance: A General Alternative Interpretation of Cross-Sectional Research on Organizations', Organizational Behavior and Human Performance 13, 414432.

Stevenson, T. H. and C. D. Bodkin: 1998, 'A Cross-National Comparison of University Students' Perceptions Regarding the Ethics and Acceptability of Sales Practices', Journal of Business Ethics 17, 4555.

Swimberghe, K., L. A. Flurry and J. M. Parker: 2011, 'Consumer Religiosity: Consequences for Consumer Activism in the United States', Journal of Business Ethics 103, 453-467.

Swimberghe, K., D. Sharma and L. W. Flurry: 2011, 'Does a Consumer’s Religion Really Matter in the Buyer-Seller Dyad? An Empirical Study Examining the Relationship between Consumer Religious Commitment, Christian Conservatism and the Ethical Judgment of a Seller’s Controversial Business Decision', Journal of Business Ethics 102, 581-598.

*Tansey, R., M. R. Hyman and G. Brown: 1992, 'Ethical Judgments about Wartime Ads Depicting Combat', Journal of Advertising 21(3), 57-74.

*Tansey, R., G. Brown, M. R. Hyman and L. E. Dawson, Jr: 1994, 'Personal Moral Philosophies and the Moral Judgments of Salespeople', Journal of Personal Selling and Sales Management 14(1), 59-74.

Taylor, E. Z. and M. B. Curtis: 2010, 'An Examination of the Layers of Workplace Influences in Ethical Judgments: Whistleblowing Likelihood and Perseverance in Public Accounting', Journal of Business Ethics 93, 21-37.

Thoma, S.J., J. R. Rest and M. L. Davison: 1991, 'Describing and Testing a Moderator of the Moral Judgment and Action Relationship', Journal of Personality and Social Psychology 61, 659-669.

Tsalikis, J. and M. Ortiz-Buonafina: 1990, 'Ethical Beliefs' Differences of Males and Females', Journal of Business Ethics 9, 509-517.

Tsalikis, J. and M. S. LaTour: 1995, 'Bribery and Extortion in International Business: Ethical Perceptions of Greeks Compared to Americans', Journal of Business Ethics 14, 249-264. 
Tsalikis, J. and O. Nwachukwu: 1991, 'A Comparison of Nigerian to American Views of Bribery and Extortion in International Commerce', Journal of Business Ethics 10, 85-98.

Tsalikis, J., B. Seaton and P. L. Shepherd: 2001, 'Relativism in Ethical Research: A Proposed Model and Mode of Inquiry', Journal of Business Ethics 32, 231-246.

Tsalikis, J., B. Seaton, B. and P. Tomaras: 2002, 'A New Perspective on Cross-Cultural Ethical

Evaluations: The Use of Conjoint Analysis', Journal of Business Ethics 35, 281-292.

*Tuttle, B., A. Harrell and P. Harrison: 1997, 'Moral Hazard, Ethical Considerations, and the Decision to Implement an Information System' Journal of Management Information Systems 13(4), 7-27. (R) Valentine, S. and T. Barnett: 2007, 'Perceived Organizational Ethics and the Ethical Decisions of Sales and Marketing Personnel', Journal of Personal Selling and Sales Management 27, 373-388. (H)

Valentine, S. R. and C. R. Bateman: 2011, 'The Impact of Ethical Ideologies, Moral Intensity, and Social Context on Sales-Based Ethical Reasoning', Journal of Business Ethics 102, 155-168.

Valentine, S. and G. Fleischman: 2003, 'Ethical Reasoning in an Equitable Relief Innocent Spouse Context', Journal of Business Ethics 45, 325-339.

Valentine, S., G. M. Fleischman, R. Sprague and L. Godkin: 2010, 'Exploring the Ethicality of Firing Employees Who Blog', Human Resource Management 49, 87-108. (H)

Valentine, S. and D. Hollingsworth: 2012, 'Moral Intensity, Issue Importance, and Ethical reasoning in Operations Situations', Journal of Business Ethics 108, 509-523.

Valentine, S. R. and K. Page: 2006, 'Nine to Five: Skepticism of Women’s Employment and Ethical Reasoning', Journal of Business Ethics 63, 53-61.

*Valentine, S. R. and T. L. Rittenburg: 2004, 'Spanish and American Professionals’ Ethical Evaluations in Global Situations', Journal of Business Ethics 51, 1-13. (H)

Valentine, S. R. and T. L. Rittenburg: 2007, 'The Ethical Decision Making of Men and Women Executives in International Business Situations', Journal of Business Ethics 71, 125-134.

Verbeke, W., C. Uwerkerk, and E. Peelen: 1996, 'Exploring the Contextual and Individual Factors on Ethical Decision Making of Salespeople', Journal of Business Ethics 15, 1175-1187. 
Vitell, S. J., A. Bakir, J. G. P. Paolillo, E. R. Hidalgo, J. Al-Khatib and M. Y. A. Rawwas: 2003, 'Ethical Judgments and Intentions: A Multinational Study of Marketing Professionals', Business Ethics: A European Review 12, 151-171. (H)

Vitell, S. J. and F. N. Ho: 1997, 'Ethical Decision Making in Marketing: A Synthesis and Evaluation of Scales Measuring the Various Components of Decision Making in Ethical Situations', Journal of Business Ethics 16, 699-717.

Vitell, S. J. and J. Muncy: 1992, 'Consumer Ethics: An Empirical Investigation of Factors Influencing Ethical Judgments of the Final Consumer', Journal of Business Ethics 11, 585-597.

Vitell, S. J. and A. Patwardhan: 2008, 'The Role of Moral Intensity and Moral Philosophy in Ethical Decision-Making: A Cross-Cultural Comparison of China and the European Union', Business Ethics: A European Review 17, 196-209.

*Wagner, S. C. and G. L. Sanders: 2001, 'Considerations in Ethical Decision-Making and Software Piracy', Journal of Business Ethics 29, 161-167.

Westerman, J. W., R. I. Beekun, Y. Stedham and J. H. Yamamura: 2007, 'Peers versus National Culture: An Analysis of Antecedents to Ethical Decision-Making,' Journal of Business Ethics 75, 239-252. (H) Wimalasiri, J. S., F. Pavri and A. A. K. Jalil: 1996, 'An Empirical Study of Moral Reasoning among Managers in Singapore', Journal of Business Ethics 15, 1331-1341.

Wu, C.: 2003, 'A Study of the Adjustment of Ethical Recognition and Ethical Decision-Making of Managers-To-Be across the Taiwan Strait Before and After Receiving a Business Ethics Education', Journal of Business Ethics 45, 291-307.

*Yoon, C.: 2011a, 'Ethical Decision-Making in the Internet Context: Development and Test of an Initial Model Based on Moral Philosophy’, Computers in Human Behavior 27, 2401-2409. (R/H)

*Yoon, C.: 2011b, 'Theory of Planned Behavior and Ethics Theory in Digital Piracy: An Integrated Model', Journal of Business Ethics 100, 405-417. (H)

*Yoon, C.: 2012, ‘Digital Piracy Intention: A Comparison of Theoretical Models’, Behaviour and Information Technology 31, 565-576. (H) 
Zhang, J., R. Chiu and L. Wei: 2009a, 'Decision-Making Process of Internal Whistleblowing Behavior in China: Empirical Evidence and Implications', Journal of Business Ethics 88, 25-41. (H)

Zhang, J., R. Chiu, R. and L. Q. Wei: 2009b, 'On Whistleblowing Judgment and Intention: The Roles of Positive Mood and Ethical Culture', Journal of Managerial Psychology 24, 627-649. (H)

* Indicates a study that reported the results of factor analyses of scores on ethical judgments survey items.

(R) Refers to a study that basically did no more than essentially replicate Reidenbach and Robin (1990).

(H) Refers to a study that advanced at least one specific hypothesis concerning connections between ethical judgments and behavioral intentions (or between different indicators of intentions). 


\section{TABLE 1}

The Multidimensional Ethics Scale (MES; Reidenbach and Robin, 1990)

\section{Broad-Based Moral Equity}

Just-Unjust

Fair-Unfair

Morally Right-Not Morally Right

Acceptable to My Family-Not Acceptable to My Family

\section{Relativism}

Culturally Acceptable-Culturally Unacceptable

Traditionally Acceptable-Traditionally Unacceptable

\section{Contractualism}

Violates an Unspoken Promise-Does Not Violate an Unspoken Promise Violates an Unwritten Contract-Does Not Violate an Unwritten Contract 


\section{TABLE 2}

\section{Nomenclature Used to Denote the Construct Measured with MES Survey Items}

\section{Study}

Beekun, Stedham, and Yamamura, 2003

Beekun, Westerman, and Barghouti, 2005

Beekun et al., 2008

Bucar, Glas, and Hisrich, 2003

Buchan, 2005

Cohen, Pant, and Sharp, 1996

Cohen, Pant, and Sharp, 1998

Cohen, Pant, and Sharp, 2001

Dean, 2004

Ellis and Griffith, 2001

Emerson, Conroy, and Stanley, 2007

Fennell and Malloy, 1999

Fleischman and Valentine, 2003

Ge and Thomas, 2008

Henderson and Kaplan, $2005^{\text {a }}$

Herndon, Fraedrich, and Yeh, 2001

Hudson, 2007

Hudson and Miller, 2005

Hudson, Hudson, and Peloza, 2008

Kaplan, Samuels, and Thorne, 2009

Landeros and Plank, 1996

LaTour, Snipes, and Bliss, 1996

Lin and Ho, 2008

\section{Label}

"Criteria used to evaluate ethical content"

“Moral philosophy”

"Ethical Perspective”

"Ethical responsiveness and/or ethical sensitivity"

"Moral sensitivity"

"Ethical Awareness"

"Ethical orientation on a number of moral constructs"

"Ethical awareness” and “moral awareness”

“Morality” and "fairness"

“Ethical perceptions” (see hypotheses)

“Ethical decision-making”

"Ethical nature”

"Ethicality of the issue" and "ethical appraisals"

"Post-conventional stage MES factors"

"Ethical evaluations"

“Individual moral values”

"Ethical orientation”

"Ethical orientation and awareness"

"Ethical orientation and awareness"

"Ethical perceptions"

"Multidimensional measure of ethicalness"

"Ethics”

“Ethical awareness” 
Loo, 2002

Loo, 2004

Mittal and Lassar, 2000

Rittenburg and Valentine, 2002

Sarwono and Armstrong, 2001

Schmidt, McAdams, and Foster, 2009

Schwepker, 1999

Schwepker, Farrell, and Ingram, 1997

Schwepker and Ingram, 1996

Shaw, 2003

Shawver and Sennetti, 2009

Smith, Simpson, and Huang, 2007

Snipes, LaTour, and Bliss, 1999

Stevenson and Bodkin, 1998

Tsalikis and Ortiz-Buonafina, 1990

Tsalikis, Seaton, and Tomaras, 2002

Tuttle, Harrell, and Harrison, 1997

Valentine and Page, 2006

Wagner and Sanders, 2001
"Ethical theories"

“Ethics scale and constructs”

"Ethical justness"

“Ethicality” (p. 296) and “ethical perceptions” (p. 297)

"Level of awareness of an ethical problem”

"Ethical reasoning”

"Moral values"

"Individual moral value frameworks"

"Moral judgment” and "more ethical decisions"

"Moral attitudes”

“Ethical awareness” and “ethical sensitivity”

“Moral evaluations”

"Ethical level”

"Ethical sensitivity”

“Ethical perceptions” and "ethical sensitivity”

"Ethical perceptions"

“Ethical considerations”

“Overall ethical sensitivity”

“Attitudes toward major issues or general constructs”

a see also Reidenbach and Robin, 1988; Jones and Middleton, 2007; Smith and Cooper-Martin, 1997;

Spicer, Dunfee, and Bailey, 2004 


\section{TABLE 3}

\section{Examples of Author Inferences (and Alternative Interpretations)}

Ayers and Kaplan, 2005, p. 134

“A strong positive correlation ... between personal responsibility ... and the moral equity dimension ... suggests that personal responsibility has a large moral component” (persons who felt a personal responsibility to inform management about the questionable activities of outside consultants tended to believe that such informing was also fair and just).

Beekun, Westerman, and Barghouti, 2005, p. 238

"Americans will rely on egoism more than Russians in determining behavioral intentions" (the egoism-behavioral intentions relationship will differ between Americans and Russians).

Beekun, Westerman, and Barghouti, 2005, p. 243

"Both Americans and Russians use relativism when determining how to behave” (relativism scores related significantly with behavioral intentions in both samples).

Beekun, Hamdy, Westerman, and HassabElnaby, 2008, p. 599

"In complete support of H8, both Egyptians and Americans relied on relativism as a criterion for the [sic] own behavioral intentions" (ethical judgments on the relativism scale related strongly to behavioral intentions in both samples).

Beekun, Stedham, Westerman, and Yamamura, 2010, Abstract

Women "relied on" justice (women tended to view ethically questionable actions as wrong on a justice measure).

Cohen, Pant, and Sharp, 1993, p. 19

"Our subjects incorporate utilitarian analysis in their ethical decision-making process" (subjects merely responded to utilitarian survey items).

Cohen, Pant, and Sharp, 1996, p. 110

"Respondents were most aware that the actions described in these vignettes were culturally/traditionally unacceptable” (respondents tended to interpret ethically questionable actions as 
inappropriate on relativistic criteria).

Davis, Andersen, and Curtis, 2001, p. 48

“Idealism is positively related to the use of justice concepts” (high idealists tended to regard ethically questionable activities as inappropriate).

Eweje and Brunton, 2010

“[F]emales appear to demonstrate a greater sensitivity in ethical awareness” (women tended to regard ethically questionable activities as less appropriate than men).

Fennell and Malloy, 1999, p. 940

“Ecotour, adventure, and fishing operators employed the justice scale to a greater extent than did the golf/cruiseline operators” (golf/cruiseline operators scored differently on the justice scale than other types of tour operators).

Ge and Thomas, 2008, p. 198

"For Canadians, more subjects made unethical than ethical decisions in two of the four cases" (most subjects indicated that the vignette protagonist would likely perform as ordered by her boss in these cases).

Hudson and Miller, 2005, p. 391

Compared with Canadians and Australians, British students "were more teleological in their decision making” (British students were more likely than others to regard the questionable activities as producing greater benefit).

Jung, 2009, p. 947

“The significantly high regression coefficient for the moral equity dimension in Scenario 2 indicated that the students perceived their peers' behavioral intentions to be based mostly on moral equity” (students who viewed the questionable activity as inappropriate on the moral equity dimension also indicated that their peers would not likely perform the activity).

Kujala, 2001, p. 243

“Teleological thinking was strongly represented in the managers’ moral decision-making 
dimensions” (managers responded to teleological survey items and factor analysis confirmed a teleological factor).

Kujala, Lamsa, and Penttila, 2011, p. 191, Abstract

"It is concluded that relying on the utilitarian principles is a core ethical evaluation criterion amongst top business managers in Finland” (a utilitarian factor emerged in responses to utilitarian survey items).

LaFleur, Reidenbach, Robin, and Forrest, 1996, p. 69

"For each of the two scenarios, the advertising practitioners recognized, to some degree, an ethical issue” (respondents were inclined to view ethically questionable activities as wrong on MES scales).

Lin and Ho, 2008, p. 1218

"The overall ethical awareness of the US accounting students is higher than that of their Taiwanese counterparts in all three scenarios” (American students regarded the ethically questionable activities as less appropriate than Taiwanese students).

Landeros and Plank, 1996, p. 795

"Respondents thought ... that the vignette did not present a contractual ethical issue" (contractualism scores correlated negatively with scores on other MES scales, perhaps because the direction of scoring was reversed for this scale).

Nguyen, Basuray, Smith, Kopka, and McCulloh, 2007, p. 425

"Both men and women were consistent in using moral equity and relativism in making judgments regarding the ethicality of an action” (men and women both responded to moral equity and relativism survey items designed to measure judgments).

Oumlil and Balloun, 2009, p. 471

“Female business managers have higher sensitivity in terms of their ethical judgment” (for two of four vignettes, women were less inclined than men to intend to "act in the same manner as the (business person) did in the above scenario”, p. 466) 
Reidenbach and Robin, 1990, p. 649

"Individuals tend to rely on a broad sense of moral equity" (moral equity is an important dimension of ethical judgments).

Rittenburg and Valentine, 2002, p. 297

Spanish executives "perceived slightly higher relativism than did the American executives" (relativism scores simply differed between the two groups as the perception of relativism was not assessed).

Shaw, 2003, p. 315

“These webmasters think more like their coworkers” (respondents who judged actions as ethically inappropriate indicated that co-workers would also judge these similarly).

Shawver and Sennetti, 2009, p. 674

"For example, one respondent may sense that an action now . . . is more unethical and therefore has less justice (the justice score decreases)" (respondents who believe that an action is unethical will also view it as unfair and unjust).

Tsalikis and Ortiz-Buonafina, 1990, p. 515

"Women view Scenario A as less relativistic" (women and men simply attained different relativism scores, as the relativism of scenarios was not assessed).

Tsalikis, Seaton, and Shepherd, 2001, p. 242

“The perceived level of a transgression increased with . . . the dollar amount of the 'loss' of the victim" (activities in which victims lost a lot of money were judged as more inappropriate than those in which less money was lost).

Valentine and Rittenburg, 2004, pp. 7-8

“American business professionals scored higher in ethicality than did the Spanish persons and appeared more ethically oriented" (relative to Spanish respondents, Americans tended to regard ethically questionable activities as less appropriate). 
Valentine and Rittenburg, 2007, p. 127, Hypothesis

“After controlling for individual differences, women’s generalized ethical reasoning is higher than men’s ethical reasoning” (women were predicted to regard ethically questionable activities as less appropriate than men).

Westerman, Beekun, Stedham, and Yamamura, 2007, p. 243

Some "cultures are more likely [than others] to use peers as a primary referent for ethical decision making behavior” (the relationship between behavioral intentions and respondent assessments of peers' behavioral intentions will differ in different cultures).

Note: Emphasis added. Alternative interpretations appear in parentheses following quotes from each paper cited.. 


\section{TABLE 4}

\section{Research Comparing Ethical Judgments Between and Among Different Groups}

Bailey and Spicer, 2007: Judgments of American expatriates working in Russia did not differ from those of Russians.

Beekun, Hamdy, Westerman, and HassabElnaby, 2008: Americans regarded questionable actions as more unethical than Egyptians on only the "justice” scale (non-significant differences appeared in three other scales).

Beekun, Stedham, Westerman, and Yamamura, 2010: No differences in judgments appeared between and among German, Italian, and Japanese respondents.

Beekun, Stedham, and Yamamura, 2003: Brazilian respondents were less likely than Americans to interpret actions as unethical on utilitarian criteria, but no differences emerged on egoistic criteria. Beekun, Westerman, and Barghouti, 2005: No differences in judgments appeared between Americans and Russians on two scales. Russians scored higher on a third scale (utilitarianism) and lower on a fourth (justice).

Bucar, Glas, and Hisrich, 2003: Compared with Americans and Slovenians, Russian respondents displayed "the lowest levels of ethical responsiveness" (p. 276). "Slovenians were very critical on the dimension of 'fairness' or 'honesty', but they fell below the American level on the pragmatic dimension of good/bad” (pp. 276-277). Entrepreneurs were also “ethically more sensitive than managers” (p. 276). Unclear in this discussion is whether, for example, Slovenians regarded questionable activities as more or less appropriate than Americans.

Cherry, Lee, and Chien, 2003: Taiwanese respondents found bribery to be more ethical, acceptable (deonotological evaluations), correct, and moral (ethical judgments) than Americans, but no differences emerged on teleological evaluations.

Cohen, Pant, and Sharp, 1995: Auditors from three Latin American countries tended to view questionable actions as less ethically appropriate than Americans. Japanese auditors were also surveyed. 
Cohen, Pant, and Sharp, 1998: Accounting majors tended to interpret the questionable actions in three vignettes as less ethically appropriate than other students.

Cohen, Pant, and Sharp, 2001: Only one difference emerged (p. 327) in judgments between and among accounting professionals, senior-level accounting students, and entry-level accounting students.

Fennell and Malloy, 1999: Ethical judgments scores in response to tourism vignettes were compared in different types of tourism operators. Members of the "ecotourism” group tended to interpret the questionable actions as most inappropriate.

Ge and Thomas, 2008: This study compared judgments of Canadian and Chinese accounting students, but results seemed difficult to interpret precisely. Respondents saw a vignette about an auditor ordered to revise a document to eliminate negative comments, and were first asked to indicate whether the auditor would or would not revise the document (p. 208; there was a third "don't know” option, but the authors interpreted this response as having made "the unethical decision” (p. 198), presumably that the auditor would acquiesce to revising the document). Next, respondents were asked to judge the ethicality of the auditor's decision that possibly was the one provided by respondents themselves. Consequently, it seems likely that not all individuals necessarily evaluated the same decision, even before the authors inserted their own interpretations of respondent choices.

Hebert, Bass, and Tomkiewicz, 2002: Ethical judgments scores were compared between managers in family owned businesses and managers in other businesses, but no differences emerged.

Henthorne, Robin, and Reidenbach, 1992: Managers tended to regard questionable actions as less ethically appropriate than salespeople.

Herndon, Fraedrich, and Yeh, 2001: Managers scored only slightly higher than salespeople on “individual moral values” (p. 77) and Taiwanese and American respondents did not differ on ethical judgments.

Hudson, 2007: No differences emerged between adults and students concerning the perceived ethicality of the decision to visit Myanmar.

Hudson and Miller, 2005: British tourism students scored lower than Australians and Canadians on utilitarianism and higher on contractualism (deontology). 
Hudson, Hudson, and Peloza, 2008: British parents regarded presence of ethically charged products in movies targeted at children as more appropriate than Canadian parents in some cases and less appropriate in others.

Humphreys, Robin, Reidenbach, and Moak, 1993: Business owners scored higher than customers on three dimensions of ethical judgments, and lower on three other dimensions.

Lin and Ho, 2008: American accounting students tended to view questionable accounting activities as more inappropriate than Taiwanese accounting students.

Oumlil and Balloun, 2009: Although unspecified differences in intentions between Moroccan and American respondents were hypothesized (p. 464), this hypothesis was apparently tested by examining differences in the strength of the relationships between judgments and intentions (pp. 470-471).

Patel, 2003: Accountants from Australia interpreted questionable actions as less appropriate than ChineseMalaysian or Indian accountants.

Rittenburg and Valentine, 2002: Spanish respondents viewed questionable actions as less appropriate than Americans on the relativism dimension.

Sarwono and Armstrong, 2001: Batak Indonesian respondents were more likely than Javanese or Chinese respondents to interpret questionable activities as ethically inappropriate.

Schmidt, McAdams, and Foster, 2009: The ethical judgments of students in an experimental section of a business ethics course did not differ from those of other business ethics students.

Shafer, 2008: Chinese auditors employed by international firms tended to judge questionable actions as less appropriate than auditors of local Chinese firms.

Spicer, Dunfee, and Bailey, 2004: American expatriates working in Russia tended to view questionable activities from six vignettes as more ethically appropriate than Americans generally.

Tsalikis and LaTour, 1995: Greek students tended to judge bribery as somewhat more ethically appropriate than American students.

Tsalikis and Nwachukwu, 1991: Nigerian students tended to judge bribery as somewhat more ethically appropriate than American students. 
Tsalikis, Seaton, and Tomaras, 2002: Greeks apparently tended to regard the questionable act as less appropriate than Americans (“Greeks 'appear' more ethically sensitive”, p. 289)

Valentine and Rittenburg, 2004: Americans tended to find questionable actions as less appropriate than Spanish respondents. 